\title{
Neurotoxin and Alpha-Neurotoxin Time-Resolved Absorption and Resonance FT-IR and Raman Bio spectroscopy and Density Functional Theory (DFT) Investigation of Vibrionic-Mode Coupling Structure in Vibrational Spectra Analysis
}

\author{
Alireza Heidari ${ }^{1,2 *}$, Jennifer Esposito ${ }^{1}$ and Angela Caissutti ${ }^{1}$ \\ ${ }^{1}$ Faculty of Chemistry, California South University, USA \\ ${ }^{2}$ American International Standards Institute, USA \\ *Corresponding author: Alireza Heidari, Faculty of Chemistry, California South University, 14731 Comet St. Irvine, CA 92604, USA. \\ To Cite This Article: Alireza Heidari. Neurotoxin and Alpha-Neurotoxin Time-Resolved Absorption and Resonance FT-IR and Raman Bio \\ spectroscopy and Density Functional Theory (DFT) Investigation of Vibrionic-Mode Coupling Structure in Vibrational Spectra Analysis. Am J \\ Biomed Sci \& Res. 2019 - 3(6). AJBSR.MS.ID.000738. DOI: 10.34297/AJBSR.2019.03.000738
}

Received: April 24, 2019 | Published: July 11, 2019

\section{Abstract}

$\alpha$-Neurotoxins are a group of neurotoxic peptides found in the venom of snakes in the families Elapidae and Hydrophiidae. They can cause paralysis, respiratory failure, and death. Members of the three-finger toxin protein family, they are antagonists of post-synaptic nicotinic acetylcholine receptors (nAChRs) in the neuromuscular synapse that bind competitively and irreversibly, preventing synaptic acetylcholine (ACh) from opening the ion channel. Over $100 \alpha$-neurotoxins have been identified and sequenced. Parameters such as FT-IR and Raman vibrational wavelengths and intensities for single crystal Neurotoxin and Alpha-Neurotoxin are calculated using density functional theory and were compared with empirical results.

The investigation about vibrational spectrum of cycle dimers in crystal with carboxyl groups from each molecule of acid was shown that it leads to create Hydrogen bounds for adjacent molecules. The current study aimed to investigate the possibility of simulating the empirical values. Analysis of vibrational spectrum of Alpha-Neurotoxin is performed based on theoretical simulation and FT- IR empirical spectrum and Raman empirical spectrum using density functional theory in levels of F/6-31G*, HF/6- 31++ $\mathrm{G}^{* *}, \mathrm{MP} 2 / 6-31 \mathrm{G}, \mathrm{MP} 2 / 6-31++\mathrm{G}^{* *}, \mathrm{BLYP} / 6-31 \mathrm{G}, \mathrm{BLYP} / 6-31++\mathrm{G}^{* *}$, B3LYP/6-31G and B3LYP6-31-HEG**. Vibration modes of methylene, carboxyl acid and phenyl cycle are separately investigated. The obtained values confirm high accuracy and validity of results obtained from calculations [1-42] (Figure 1).

Figure 1: Molecular structure of Neurotoxin (left) and Alpha-Neurotoxin (right).

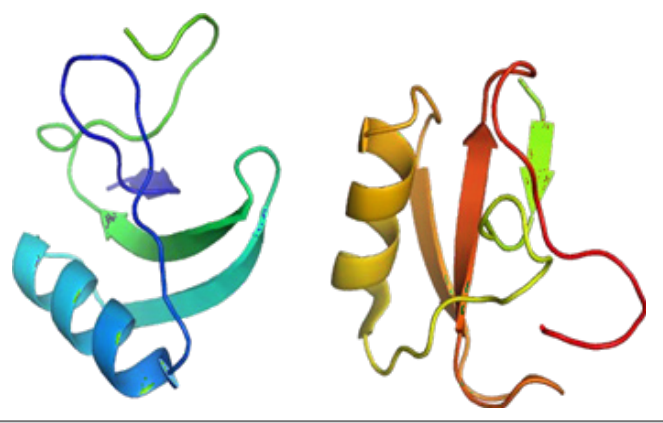

Keywords: Vibrionic Structure; Vibrational Spectra Analysis; Density Functional Theory (DFT); Alpha-Neurotoxin; non-Focal Functions of Becke; Correlation Functions of Lee-Yang-Parr; Time-Resolved Absorption and Resonance; FT-IR and Raman Bio spectroscopy 


\section{Introduction}

$\alpha$-Neurotoxins are a group of neurotoxic peptides found in the venom of snakes in the families Elapidae and Hydrophiidae. They can cause paralysis, respiratory failure, and death. Members of the three-finger toxin protein family, they are antagonists of post-synaptic nicotinic acetylcholine receptors (nAChRs) in the neuromuscular synapse that bind competitively and irreversibly, preventing synaptic acetylcholine (ACh) from opening the ion channel. Over $100 \alpha$ - neurotoxins have been identified and sequenced.

Density Functional Theory (DFT) is one of the most powerful calculation methods for electronic structures [5-7]. Numerous results have been previously studied and indicate successful use of these methods [8-10]. The theory is one of the most appropriate methods for simulating the vibrational wavenumbers, molecular structure as well as total energy. It may be useful to initially consider the calculated results by density functional theory using F/6-31G*, HF/6-31++G**, MP2/6-31G, MP2/6-31++G**, BLYP/6- 31G, BLYP/6-31++G**, B3LYP/6-31G and B3LYP6-31-

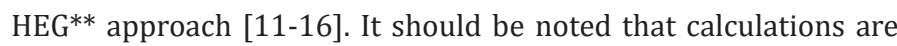
performed by considering one degree of quantum interference as well as polarization effects of $2 \mathrm{~d}$ orbitals in interaction [17-320].

\section{Details of Calculations}

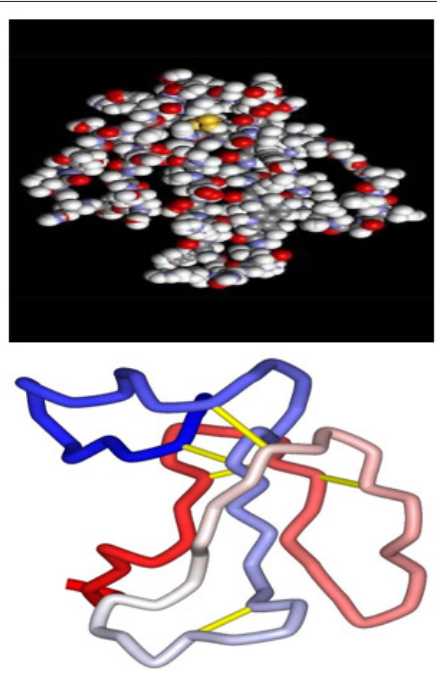

Figure 2: Different sections of the Neurotoxin (upper) and AlphaNeurotoxin (lower) [43-93].

All calculations of molecular orbital in the base of ab are performed by Gaussian 09. In calculation process, the structure of Alpha-Neurotoxin molecule (Figure 2) is optimized and FT- IR and Raman wavenumbers are calculated using F/6-31G*, HF/6$31++G^{* *}, \quad M P 2 / 6-31 G, \quad M P 2 / 6-31++G^{* *}$, BLYP/6-31G, BLYP/631++G** B3LYP/6-31G and B3LYP6-31-HEG** base. All optimized structures are adjusted with minimum energy. Harmonic vibrational wavenumbers are calculated using second degree of derivation to adjust convergence on potential surface as good as possible and to evaluate vibrational energies at zero point. In optimized structures considered in the current study, virtual frequency modes are not observed which indicates that the minimum potential energy surface is correctly chosen. The optimized geometry is calculated by minimizing the energy relative to all geometrical quantities without forcing any constraint on molecular symmetry. Calculations were performed by Gaussian 09.

The current calculation is aimed to maximize structural optimization using density functional theory. The calculations of density functional theory are performed by F/6-31G*, HF/631++G**, MP2/6-31G, MP2/6-31++G**, BLYP/6-31G, BLYP/6$31++G^{* *}, B 3 L Y P / 6-31 G$ and B3LYP6-31-HEG** function in which non-focal functions of Becke and correlation functions of Lee-YangParr beyond the Franck-Condon approximation are used. After completion of optimization process, the second order derivation of energy is calculated as a function of core coordination and is investigated to evaluate whether the structure is accurately minimized. Vibrational frequencies used to simulate spectrums presented in the current study are derived from these second order derivatives. All calculations are performed for room temperature of $316(\mathrm{~K})$.

\section{Vibration Analysis}

Analysis of vibrational spectrum of Alpha-Neurotoxin is performed based on theoretical simulation and FT-IR empirical spectrum and Raman empirical spectrum using density functional theory in levels of F/6-31G*, HF/6-31++G**, MP2/6-31G, MP2/6$31++\mathrm{G}^{* *}, \quad \mathrm{BLYP} / 6-31 \mathrm{G}, \mathrm{BLYP} / 6-31++\mathrm{G}^{* *}, \mathrm{~B} 3 \mathrm{LYP} / 6-31 \mathrm{G}$ and B3LYP6-31-HEG**. Vibration modes of methylene, carboxyl acid and phenyl cycle are separately investigated. C-H stretching vibrations in single replacement of benzene cycles are usually seen in band range of 3250-3650 cm-1. Weak Raman bands are at 3191 $\mathrm{cm}-1$ and $3207 \mathrm{~cm}-1$. C-C stretching mode is a strong Raman mode at $1211 \mathrm{~cm}-1$. Raman weak band is seen at $1687 \mathrm{~cm}-1$ too. Bending mode of C-H is emerged as a weak mode at $1429 \mathrm{~cm}-1$ and 1205 cm-1 and a strong band at $1289 \mathrm{~cm}-1$ in Raman spectrum. Raman is considerably active in the range of $1250-1650 \mathrm{~cm}-1$ which 1199 $\mathrm{cm}-1$ indicates this issue.

$\mathrm{C}-\mathrm{H}$ skew-symmetric stretching mode of methylene group is expected at $3189 \mathrm{~cm}-1$ and its symmetric mode is expected at $3000 \mathrm{~cm}-1$. Skew-symmetric stretching mode of $\mathrm{CH} 2$ in AlphaNeurotoxin has a mode in mid-range of Raman spectrum at 3250$3650 \mathrm{~cm}-1$. When this mode is symmetric, it is at $3099 \mathrm{~cm}-1$ and is sharp. The calculated wavenumbers of higher modes are at 3073 cm-1 and $3096 \mathrm{~cm}-1$ for symmetric and skew-symmetric stretching mode of methylene, respectively.

Scissoring vibrations of $\mathrm{CH} 2$ are usually seen at the range of 1530-1590 cm-1 which often includes mid-range bands. Weak bands at $1550 \mathrm{~cm}-1$ are scissoring modes of $\mathrm{CH} 2$ in Raman spectrum. Moving vibrations of methylene are usually seen at $1479 \mathrm{~cm} \mathrm{-1.} \mathrm{For} \mathrm{the} \mathrm{investigated} \mathrm{chemical} \mathrm{in} \mathrm{the} \mathrm{current} \mathrm{study,}$ these vibrations are at $1349 \mathrm{~cm}-1$ were calculated using density functional theory. Twisting and rocking vibrations of $\mathrm{CH} 2$ are seen in Raman spectrum at $925 \mathrm{~cm}-1$ and $1191 \mathrm{~cm}-1$, respectively, which are in good accordance with the results at $907 \mathrm{~cm}-1$ and $1167 \mathrm{~cm}$ 1 , respectively. In a non-ionized carboxyl group $(\mathrm{COOH})$, stretching 
vibrations of carbonyl $[\mathrm{C}=0$ ] are mainly observed at the range of 1850-1898 cm-1. If dimer is considered as an intact constituent, two stretching vibrations of carbonyl for symmetric stretching are at 1750-1795 cm-1 in Raman spectrum. In the current paper, stretching vibration of carbonyl mode is at $1799 \mathrm{~cm}-1$ which is a mid-range value.

Stretching and bending bands of hydroxyl can be identified by width and band intensity which in turn is dependent on bond length of Hydrogen. In dimer form of Hydrogen bond, stretching band of $\mathrm{O}-\mathrm{H}$ is of a strong Raman peak at $1377 \mathrm{~cm}-1$ which is due to in-plain metamorphosis mode. Out-of-plain mode of $\mathrm{O}-\mathrm{H}$ group is a very strong mode of peak at $1056 \mathrm{~cm}-1$ of Raman spectrum. The stretching mode of $\mathrm{C}-\mathrm{O}(\mathrm{H})$ emerges as a mid-band of Raman spectrum at $1263 \mathrm{~cm}-1$. Lattice vibrations are usually seen at the range of $0-850 \mathrm{~cm}-1$. These modes are induced by rotary and transferring vibrations of molecules and vibrations and are including Hydrogen bond. Bands with low wavenumbers of Hydrogen bond vibrations in FT-IR and Raman spectrum (Figure 3) are frequently weak, width and unsymmetrical. Rotary lattice vibrations are frequently stronger than transferring ones. Intramolecular vibrations with low wavenumbers involving two-bands O-H ...O dimer at $99 \mathrm{~cm}-1,199 \mathrm{~cm}-1$ and $269 \mathrm{~cm}-1$ are attributed to a rotary moving of two molecules involving in-plain rotation of molecules against each other.

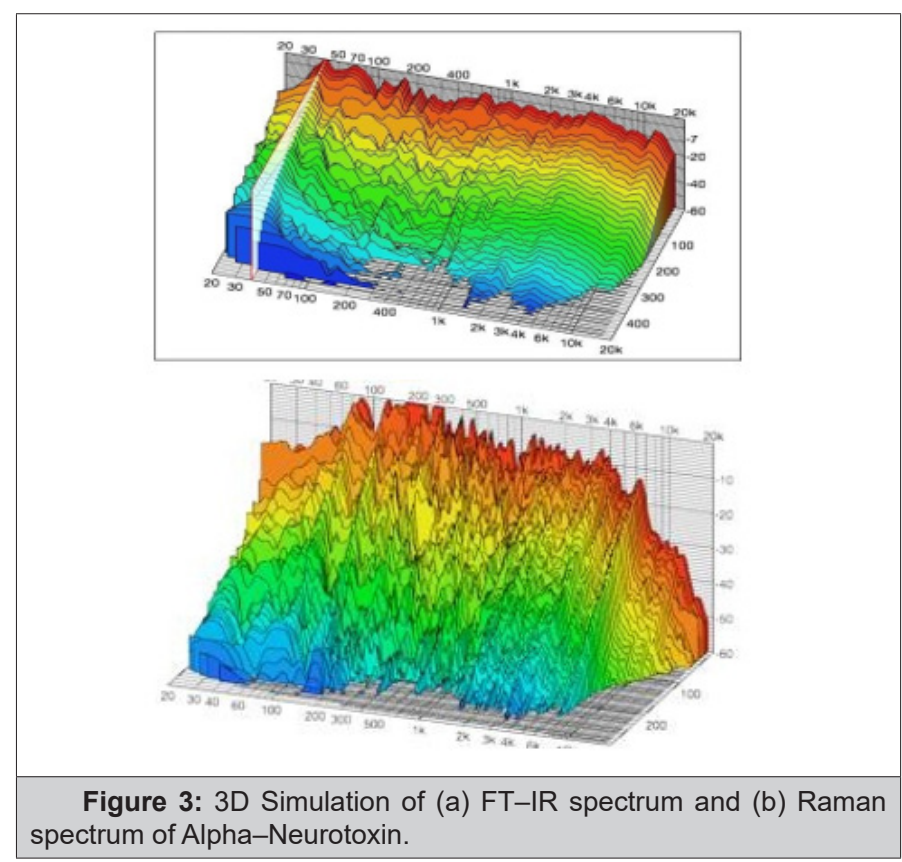

\section{Conclusion and Summary}

Calculations of density functional theory using F/6-31G*, HF/631++G**, MP2/6-31G, MP2/6-31++G**, BLYP/6-31G, BLYP/631++G**, B3LYP/6-31G and B3LYP6-31-HEG** levels were used to obtain vibrational wavenumbers and intensities in single crystal of Alpha- Neurotoxin. Investigation and consideration of vibrational spectrum confirm the formation of dimer cycles in the investigated crystal with carboxyl groups from each Hydrogen molecule of acid protected from adjacent molecules. The calculated vibrational spectrum which obtains from calculations of density functional theory is in good accordance with recorded empirical values which indicates successful simulation of the problem. The obtained results indicate that the results obtained from theoretical calculations are valid through comparing with empirical recorded results.

\section{Acknowledgements}

Authors are supported by an American International Standards Institute (AISI) Future Fellowship Grant FT1201009373493. We acknowledge Ms. Isabelle Villena for instrumental support and Dr. Michael N. Cocchi for constructing graphical abstract figure. We gratefully acknowledge Prof. Dr. Christopher Brown for proofreading the manuscript.

\section{References}

1. Yu P, Wu J, Liu S, Xiong J, Jagadish C (2016) Design and Fabrication of Silicon Nanowires towards Efficient Solar Cells. Nano Today 11(6): 704 737.

2. Sandhu S, Fan S (2015) Current-Voltage Enhancement of a Single Coaxial Nanowire Solar Cell. ACS Photonics 2(12): 1698- 1704.

3. Van Dam D, Van Hoof, N J J, Cui Y, Peter J van Veldhoven, et al. (2016) High-Efficiency Nanowire Solar Cells with Omnidirectionally Enhanced Absorption Due to Self-Aligned Indium-Tin-Oxide Mie Scatterers. ACS Nano 10(12): 11414-11419.

4. S Luo, WB Yu, Y He, G Ouyang (2015) Size-Dependent Optical Absorption Modulation of $\mathrm{Si} / \mathrm{Ge}$ and $\mathrm{Ge} / \mathrm{Si}$ Core/shell Nanowires with Different Cross-Sectional Geometries. Nanotechnology 26(8).

5. Yu P, Yao Y, Wu J, Niu X, Rogach AL, et al. (2017) Effects of Plasmonic Metal Core- Dielectric Shell Nanoparticles on the Broadband Light Absorption Enhancement in Thin Film Solar Cells. Scientific Reports 7.

6. Gouda AM, Allam NK, Swillam MA (2017) Efficient Fabrication Methodology of Wide-Angle Black Silicon for Energy Harvesting Applications. RSC Advances 7(43): 26974- 26982.

7. Branz HM, Yost VE, Ward S, Jones KM, To B, et al. (2009) Nanostructured Black Silicon and the Optical Reflectance of Graded-Density Surfaces. Appl Phys Lett 94: 231121.

8. Fazio B, Artoni P, Antonia Iati M, D Andrea C, Lo Faro, et al. (2016) Strongly Enhanced Light Trapping in a Two-Dimensional Silicon Nanowire Random Fractal Array. Light: Science \& Applications 5: e16062.

9. Ko MD, Rim T, Kim K, Meyyappan M, Baek CK(2015) High Efficiency Silicon Solar Cell Based on Asymmetric Nanowire. Scientific Report 5: 11646.

10. Oh J, Yuan HC, Branz HM (2012) An 18.2\%-Efficient Black-Silicon Solar Cell Achieved through Control of Carrier Recombination in Nanostructures. Nature Nanotechnology 7: 743-748.

11. Lin H, Xiu F, Fang M, Yip S, Cheung H Y (2014) Rational Design of Inverted Nanopencil Arrays for Cost-Effective, Broadband, and Omnidirectional Light Harvesting. ACS Nano 8(4): 3752- 3760.

12. Garnett E, Yang P (2010) Light Trapping in Silicon Nanowire Solar Cells. Nano Lett 10(3): 1082-1087.

13. Misra S, Yu L, Foldyna M, Roca I Cabarrocas P (2013) High Efficiency and Stable Hydrogenated Amorphous Silicon Radial Junction Solar Cells Built on VLS-Grown Silicon Nanowires. Solar Energy Materials and Solar Cells 118: 90-95.

14. Kelzenberg MD, Boettcher SW, Petykiewicz JA, Turner Evans DB, Putnam MC, et al. (2010) Enhanced Absorption and Carrier Collection in Si Wire Arrays for Photovoltaic Applications. Nature Materials 9: 239-244.

15. Tian B, Zheng X, Kempa TJ, Fang Y, Yu N, et al. (2007) Coaxial Silicon Nanowires as Solar Cells and nanoelectronics power Sources. Nature 449: 885-889. 
16. Razek SA, Swillam MA, Allam NK (2014) Vertically Aligned Crystalline Silicon Nanowires with Controlled Diameters for Energy Conversion Applications: Experimental and Theoretical Insights. Journal of Applied Physics 115: 194305

17. Dhindsa N, Walia J, Saini SS (2016) A Platform for Colorful Solar Cells with Enhanced Absorption. Nanotechnology 27(49): 495203.

18. Dhindsa N, Walia J, Pathirane M, Khodadad I, Wong WS, et al. (2016) Adjustable Optical Response of Amorphous Silicon Nanowires Integrated with Thin Films. Nanotechnology 27(14): 145703.

19. Zhu J, Yu Z, Burkhard GF, Hsu CM, Connor ST, et al. (2009) Optical Absorption Enhancement in Amorphous Silicon Nanowire and nanocone arrays. Nano Lett 9(1): 279- 282.

20. Klinger D, Lusakowska E, Zymierska D (2006) Nanostructure Formed by Nanosecond Laser Annealing on Amorphous Si Surface. Mater. Sci Semicond Process 9: 323-326.

21. Kumar P, Krishna MG, Bhattacharya A (2009) Excimer Laser Induced Nano structuring of Silicon Surfaces. J Nanosci Nanotechno 9(5): 3224 3232.

22. Kumar P (2010) Surface Modulation of Silicon Surface by Excimer Laser at Laser Fluence below Ablation Threshold. Applied Physics A 99(1): 245-250.

23. Adikaari AADT, Silva SRP (2005) Thickness Dependence of Properties of Excimer Laser Crystallized Nano-Polycrystalline Silicon. Journal of Applied Physics 97(11): 114305

24. Adikaari AADT, Dissanayake DMNM, Hatton RA, Silva SRP (2007) Efficient Laser Textured Nanocrystalline Silicon-Polymer Bilayer Solar Cells. Appl Phys Lett 90: 203514.

25. Adikaari AADT, Silva SRP (2008) Excimer Laser Crystallization and Nano structuring of Amorphous Silicon for Photovoltaic Applications. Nano 3(3): 117-126.

26. Tang YF, Silva S R P, Boskovic B O, Shannon JM (2002) Electron Field Emission from Excimer Laser Crystallized Amorphous Silicon. Appl Phys Lett 80(22): 4154.

27. Jin S, Hong S, Mativenga M, Kim B, Shin HH, et al. (2016) Low Temperature Polycrystalline Silicon with Single Orientation on Glass by Blue Laser Annealing. Thin Solid Films 616: 838-841.

28. Crouch CH, Carey JE, Warrender JM, Aziz MJ, Mazur E, et al. (2004) Comparison of Structure and Properties of Femtosecond and Nanosecond Laser-Structured Silicon. Appl Phys Lett 84(11): 1850.

29. Wu C, Crouch CH, Zhao L, Carey JE, Younkin R (2001) Near-Unity belowBand-Gap Absorption by Microstructure Silicon. Appl Phys Lett 78(13): 1850 .

30. Pedraza AJ, Fowlkes JD (1999) Silicon Microcolumn Arrays Grown by Nanosecond Pulsed-Excimer Laser Irradiation. Appl Phys Lett 74(16): 2322.

31. Pedraza AJ, Fowlkes JD, Jesse S, Mao C, Lowndes DH (2000) Surface Micro-Structuring of Silicon by Excimer-Laser Irradiation in Reactive Atmospheres. Applied Surface Science 168(1-4): 251-257.

32. Porte HP, Turchinovich D, Persheyev S, Fan Y, Rose MJ, et al. (2013) On Ultrafast Photoconductivity Dynamics and Crystallinity of Black Silicon. IEEE Transactions on Terahertz Science and Technology 3(3): 331-341.

33. Georgiev DG, Baird RJ, Avrutsky I, Auner G (2004) Controllable ExcimerLaser Fabrication of Conical Nano-Tips on Silicon Thin Films. Appl Phys Lett 84(24): 4881.

34. Eizenkop J, Avrutsky I, Georgiev DG, Chaudchary V (2008) Single-Pulse Excimer Laser Nanostructuring of Silicon: A Heat Transfer Problem and Surface Morphology. Journal of Applied Physics 103(9): 94311.

35. Eizenkop J, Avrutsky I, Auner G (2007) Single Pulse Excimer Laser Nanostructuring of Thin Silicon Films: Nanosharp Cones Formation and a Heat Transfer Problem. Journal of Applied Physics 101(9): 94301.
36. Hong L, Wang XC, Zheng HY, He L, Wang H, et al. (2013) Femtosecond Laser Induced Nanocone Structure and Simultaneous Crystallization of $1.6 \mu \mathrm{m}$ amorphous Silicon Thin Film for Photovoltaic Application. Journal of Physics D: Applied Physics 46(19).

37. Hong L, Wang X, Rusli, Wang H, Zheng H, et al. (2012) Crystallization and Surface Texturing of Amorphous-Si Induced by UV Laser for Photovoltaic Application. Journal of Applied Physics 111(4): 43106.

38. Magdi S, Swillam MA (2017) Broadband Absorption Enhancement in Amorphous Si Solar Cells Using Metal Gratings and Surface Texturing. Proc SPIE 10099: 1009912.

39. Diedenhofen SL, Janssen OTA, Grzela G, Bakkers EPAM, Gómez Rivas J (2011) Strong Geometrical Dependence of the Absorption of Light in Arrays of Semiconductor Nanowires. ACS Nano 5(3): 2316-2323.

40. Jager ST, Strehle S (2014) Design Parameters for Enhanced Photon Absorption in Vertically Aligned Silicon Nanowire Arrays. Nanoscale Research Letters 9: 511.

41. Gouda A M, Elsayed M Y, Khalifa A E, Ismail Y, Swillam M A (2016) Lithography-Free Wide-Angle Antireflective Self-Cleaning Silicon Nanocones. Opt Lett 41(15): 3575-3578.

42. Magdi S, Swillam MA (2017) Optical Analysis of Si-Tapered Nanowires/ low Band Gap Polymer Hybrid Solar Cells. Proc. SPIE 10099.

43. Jiang Y, Gong X, Qin R, Liu H, Xia C, et al. (2016) Efficiency Enhancement Mechanism for Poly (3, 4-ethylenedioxythiophene): Poly (styrene sulfonate)/Silicon Nanowires Hybrid Solar Cells Using Alkali Treatment. Nanoscale Res Lett 11(1): 267.

44. Gong X, Jiang Y, Li M, Liu H, Ma H (2015) Hybrid Tapered Silicon nanowire/PEDOT:PSS Solar Cells. RSC Advances 14.

45. Mohammad N S (2014) Understanding Quantum Confinement in Nanowires: Basics, Applications and Possible Laws. J Phys Condens Matter 26(42): 423202

46. Zhang A, Luo S, Ouyang G, Yang G W (2013) Strain-Induced Optical Absorption Properties of Semiconductor Nanocrystals. J Chem Phys 138(24): 244702.

47. He Y, Yu W, Ouyang G (2016) Shape-Dependent Conversion Efficiency of Si Nanowire Solar Cells with Polygonal Cross-Sections. Journal of Applied Physics 119(22): 225101.

48. Tchakarov S, Das D, Saadane O, Kharchenko A V, Suendo V, et al. (2004) Helium versus Hydrogen Dilution in the Optimization of Polymorphous Silicon Solar Cells. Journal of Non-Crystalline Solids 338(340): 668-672.

49. Roszairi H, Rahman SA (2002) High Deposition Rate Thin Film Hydrogenated Amorphous Silicon Prepared by DC Plasma Enhanced Chemical Vapour Deposition of Helium Diluted Silane. IEEE 19(21): 300-303.

50. N Guyen TTT, Duong HTT, Basuki J, Montembault V, Pascual S, et al. (2013) Functional Iron Oxide Magnetic Nanoparticles with HyperthermiaInduced Drug Release Ability by Using a Combination of Orthogonal Click Reactions. Angew Chem Int Ed Engl 52(52): 14152-14156.

51. Xu Z, Zhao Y, Wang X, Lin T (2013) A Thermally Healable Polyhedral Oligomeric Silsesquioxane (POSS) Nanocomposite based on Diels-Alder chemistry. Chem Commun 49(60): 6755-6757.

52. Engel T, Kickelbick G (2014) Self-Healing Nanocomposites from SilicaPolymer Core-Shell Nanoparticles. Polym Int 63(5): 915-923.

53. Engel T, Kickelbick G (2015) Furan-Modified Spherosilicates as Building Blocks for Self-Healing Materials. Eur J Inorg Chem 2015(7): 1226-1232.

54. Torres Lugo M, Rinaldi C (2013) Thermal Potentiation of Chemotherapy by Magnetic Nanoparticles. Nanomedicine 8(10): 1689-1707.

55. Hohlbein N, Shaaban A, Bras AR, Pyckhout Hintzen W, Schmidt AM (2015) Self-healing Dynamic Bond-based Rubbers: Understanding the Mechanisms in Ionomeric Elastomer Model Systems. Phys Chem Chem Phys 17(32): 21005-21017. 
56. Wu CS, Kao TH, Li HY, Liu YL (2012) Preparation of Polybenzoxazinefunctionalized Fe304 Nanoparticles through in situ Diels-Alder Polymerization for High Performance Magnetic Polybenzoxazine/Fe304 Nanocomposites. Compos Sci Technol 72(13): 1562-1567.

57. Menon AV, Madras G, Bose S (2018) Ultrafast Self-Healable Interfaces in Polyurethane Nanocomposites Designed Using Diels-Alder Click as an Efficient Microwave Absorber. ACS Omega 3: 1137-1146.

58. Engel T, Kickelbick G (2013) Thermoreversible Reactions on Inorganic Nanoparticle Surfaces: Diels-Alder Reactions on Sterically Crowded Surfaces. Chem Mater 25(2): 149-157.

59. Schafer S, Kickelbick G (2015) Self-Healing Polymer Nanocomposites based on Diels-Alder- reactions with Silica Nanoparticles: The Role of the Polymer Matrix. Polymer 69: 357-368.

60. Park JS, Darlington T, Starr AF, Takahashi K, Riendeau J, et al. (2010) Multiple Healing Effect of Thermally Activated Self-Healing Composites based on Diels- Alder reaction. Compos Sci Technol 70(15): 2154-2159.

61. Li J, Liang J, Li L, Ren F, Hu W, et al. (2014) Healable Capacitive Touch Screen Sensors Based on Transparent Composite Electrodes Comprising Silver Nanowires and a Furan/Maleimide Diels-Alder Cycloaddition Polymer. ACS Nano 8(12): 12874-12882.

62. Sun S, Zeng H, Robinson DB, Raoux S, Rice PM, et al. (2004) Monodisperse MFe204 (M = Fe, Co, Mn) Nanoparticles. J Am Chem Soc 126(1): 273279.

63. Frison R, Cernuto G, Cervellino A, Zaharko O, Colonna GM, et al. (2013) Magnetite-Maghemite Nanoparticles in the 5-15nm Range: Correlating the Core-Shell Composition and the Surface Structure to the Magnetic Properties. A Total Scattering Study. Chem Mater 25(23): 4820-4827.

64. Santoyo Salazar J, Perez L, de Abril O, Truong Phuoc L, Ihiawakrim D, et al. (2011) Magnetic Iron Oxide Nanoparticles in 10-40 nm Range: Composition in Terms of Magnetite/ Maghemite Ratio and Effect on the Magnetic Properties. Chem Mater 23(6): 1379-1386.

65. Guerrero G, Mutin PH, Vioux A (2001) Anchoring of Phosphonate and Phosphinate Coupling Molecules on Titania Particles. Chem Mater 13(11): 4367-4373.

66. Babu K, Dhamodharan R (2008) Grafting of Poly (methyl methacrylate) Brushes from Magnetite Nanoparticles Using a Phosphonic Acid Based Initiator by Ambient Temperature Atom Transfer Radical Polymerization (ATATRP). Nanoscale Research Letters 3: 109-117.

67. Mohapatra S, Pramanik P (2009) Synthesis and Stability of Functionalized Iron Oxide Nanoparticles using Organophosphorus Coupling Agents. Colloids Surf 339(1-3): 35-42.

68. Larsen BA, Hurst KM, Ashurst WR, Serkova NJ, Stoldt CR (2012) Mono and Dialkoxysilane Surface Modification of Superparamagnetic Iron Oxide Nanoparticles for Application as Magnetic Resonance Imaging Contrast Agents. J Mater Res 27(14): 1846-1852.

69. Davis K, Qi B, Witmer M, Kitchens CL, Powell BA, et al. (2014) Quantitative Measurement of Ligand Exchange on Iron Oxides via Radiolabeled Oleic Acid. Langmuir 30(36): 10918-10925.

70. Feichtenschlager B, Pabisch S, Peterlik H, Kickelbick G (2012) Nanoparticle Assemblies as Probes for Self-Assembled Monolayer Characterization: Correlation between Surface Functionalization and Agglomeration Behavior. Langmuir 28(1): 741-750.

71. Musa OM (2016) Handbook of Maleic Anhydride Based Materials: Syntheses, Properties and Applications. Springer International Publishing Switzerland p.12.

72. Sauer R, Froimowicz P, Scholler K, Cramer JM, Ritz S, et al. (2012) Design, Synthesis and Miniemulsion Polymerization of New Phosphonate Surfmers and Application Studies of the Resulting Nanoparticles as Model Systems for Biomimetic Mineralization and Cellular Uptake. Chem-Eur J 18(17): 5201-5212.

73. Lu C, Bhatt LR, Jun HY, Park SH, Chai KY (2012) Carboxyl-Polyethylene Glycol- Phosphoric Acid: A Ligand for highly stabilized Iron Oxide Nanoparticles. J Mater Chem 22: 19806-19811.
74. Patsula V, Kosinova L, Lovric M, Ferhatovic Hamzic L, Rabyk M, et al. (2016) Superparamagnetic Fe304 Nanoparticles: Synthesis by Thermal Decomposition of Iron (III) Glucuronate and Application in Magnetic Resonance Imaging. ACS Appl Mater Interfaces 8(11): 7238-7247.

75. Pothayee N, Balasubramaniam S, Davis RM, Riffle JS, Carroll MRJ, et al. (2011) Synthesis of 'ready-to-adsorb' Polymeric Nanoshells for Magnetic Iron Oxide Nanoparticles via Atom Transfer Radical Polymerization. Polymer 52(6): 1356-1366.

76. Daou J, Begin Colin S, Grenèche JM, Thomas F, Derory A, et al. (2007) Phosphate Adsorption Properties of Magnetite Based Nanoparticles. Chem Mater 19(18): 4494-4505.

77. Breucker L, Landfester K, Taden A (2015) Phosphonic AcidFunctionalized Polyurethane Dispersions with Improved Adhesion Properties. ACS Appl Mater Interfaces 7(44): 24641-24648.

78. Sahoo Y, Pizem H, Fried T, Golodnitsky D, Burstein L, et al. (2001) Alkyl Phosphonate/Phosphate Coating on Magnetite Nanoparticles: A Comparison with Fatty Acids. Langmuir 17: 7907-7911.

79. Longo RC, Cho K, Schmidt WG, Chabal YJ, Thissen P (2013) Monolayer Doping via Phosphonic Acid Grafting on Silicon: Microscopic Insight from Infrared Spectroscopy and Density Functional Theory Calculations. Adv Funct Mater 23: 3471-3477.

80. Luschtinetz R, Seifert G, Jaehne E, Adler HJP (2007) Infrared Spectra of Alkylphosphonic Acid Bound to Aluminium Surfaces. Macromol. Symp 254(1): 248-253

81. Thomas LC, Chittenden RA (1964) Characteristic Infrared Absorption Frequencies of Organophosphorus Compounds-II. P-O-(X) Bonds Spectrochim Acta 20(3): 489-502.

82. Quinones R, Shoup D, Behnke G, Peck C, Agarwal S, et al. (2017) Study of Perfluorophosphonic Acid Surface Modifications on Zinc Oxide Nanoparticles. Materials 10(12): 1-16.

83. Lalatonne Y, Paris C, Serfaty JM, Weinmann P, Lecouvey M, et al. (2008) Bis-Phosphonates-Ultra Small Superparamagnetic Iron Oxide Nanoparticles: A Platform towards Diagnosis and Therapy. Chem Commun 22: 2553-2555

84. Jastrzebski W, Sitarz M, Rokita M, Bulat K (2011) Infrared Spectroscopy of different Phosphates Structures. Spectrochimica Acta Part A: Molecular and Biomolecular Spectroscopy 79(4): 722-727.

85. Brodard Severac F, Guerrero G, Maquet J, Florian P, Gervais C, et al. (2008) High-Field 170 MAS NMR Investigation of Phosphonic Acid Monolayers on Titania. Chem Mater 20(16): 5191-5196.

86. Brice Profeta S, Arrio MA, Tronc E, Menguy N, Letard I, et al. (2005) Magnetic Order in g-Fe203 Nanoparticles: A XMCD Study. J Magn Magn Mater 288: 354-365.

87. Tronc E, Ezzir A, Cherkaoui R, Chanéac C, Noguès M, et al. (2000) SurfaceRelated Properties of g-Fe2O3 Nanoparticles. J Magn Magn Mater 221(12): 63-79.

88. Yee C, Kataby G, Ulman A, Prozorov T, White H, et al. (1999) SelfAssembled Monolayers of Alkanesulfonic and -phosphonic Acids on Amorphous Iron Oxide Nanoparticles. Langmuir 15: 7111-7115.

89. Jolivet JP, Chaneac C, Tronc E (2004) Iron Oxide Chemistry. From Molecular Clusters to Extended Solid Networks. Chem Commun 5: 481487.

90. Campbell VE, Tonelli M, Cimatti I, Moussy JB, Tortech L, et al. (2016) Engineering the Magnetic Coupling and Anisotropy at the MoleculeMagnetic Surface Interface in Molecular Spintronic Devices. Nat Commun 7: 13646 .

91. Pabisiak T, Winiarski MJ, Ossowski T, Kiejna A (2016) Adsorption of Gold Subnano-Structures on a Magnetite (111) Surface and their Interaction with CO. Phys Chem Chem Phys 18(27): 18169-18179.

92. Gomes R, Hassinen A, Szczygiel A, Zhao Q Vantomme A, et al. (2011) Binding of Phosphonic Acids to CdSe Quantum Dots: A Solution NMR Study. J Phys Chem Lett 2(3): 145-152. 
93. Chun YJ, Park JN, Oh GM, Hong SI, Kim YJ (1994) Synthesis of $\omega$-Phthalimidoalkylphosphonates. Synthesis 1994, 909-910.

94. A Heidari, C Brown (2015) Study of Composition and Morphology of Cadmium Oxide (CdO) Nanoparticles for Eliminating Cancer Cells. J Nanomed Res 2(5): 1-20.

95. A Heidari, C Brown (2015) Study of Surface Morphological, Phytochemical and Structural Characteristics of Rhodium (III) Oxide (Rh203) Nanoparticles. International Journal of Pharmacology, Phytochemistry and Ethnomedicine 1(1):15-19.

96. A Heidari (2016) An Experimental Biospectroscopic Study on Seminal Plasma in Determination of Semen Quality for Evaluation of Male Infertility. Int J Adv Technol 7(2): e007.

97. A Heidari (2016) Extraction and Preconcentration of N-Tolyl-SulfonylPhosphoramid-Saeure-Dichlorid as an Anti-Cancer Drug from Plants: A Pharmacognosy Study. J Pharmacogn Nat Prod 2(2): e103.

98. A Heidari (2016) A Thermodynamic Study on Hydration and Dehydration of DNA and RNA-Amphiphile Complexes. J Bioeng Biomed Sci S(3): 006.

99. A Heidari (2016) Computational Studies on Molecular Structures and Carbonyl and Ketene Groups' Effects of Singlet and Triplet Energies of Azidoketene $\mathrm{O}=\mathrm{C}=\mathrm{CH}-\mathrm{NNN}$ and Isocyanatoketene $\mathrm{O}=\mathrm{C}=\mathrm{CH}-\mathrm{N}=\mathrm{C}=\mathrm{O}$. Appl Computat Math 5: e142.

100. A Heidari (2016) Study of Irradiations to Enhance the Induces the Dissociation of Hydrogen Bonds between Peptide Chains and Transition from Helix Structure to Random Coil Structure Using ATRFTIR, Raman and 1HNMR Spectroscopies. J Biomol Res Ther 5(2) e146.

101. A Heidari (2016) Future Prospects of Point Fluorescence Spectroscopy, Fluorescence Imaging and Fluorescence Endoscopy in Photodynamic Therapy (PDT) for Cancer Cells. J Bioanal Biomed 8: e135.

102. A Heidari (2016) A Bio-Spectroscopic Study of DNA Density and Color Role as Determining Factor for Absorbed Irradiation in Cancer Cells. Adv Cancer Prev 1: e102.

103. A Heidari (2016) Manufacturing Process of Solar Cells Using Cadmium Oxide (CdO) and Rhodium (III) Oxide (Rh203) Nanoparticles. J Biotechnol Biomater 6: e125.

104. A Heidari (2016) A Novel Experimental and Computational Approach to Photobiosimulation of Telomeric DNA/RNA: A Biospectroscopic and Photobiological Study. J Res Development 4: 1.

105. A Heidari (2016) Biochemical and Pharmacodynamical Study of Microporous Molecularly Imprinted Polymer Selective for Vancomycin, Teicoplanin, Oritavancin, Telavancin and Dalbavancin Binding. Biochem Physiol 5: e146.

106. A Heidari (2016) Anti-Cancer Effect of UV Irradiation at Presence of Cadmium Oxide (CdO) Nanoparticles on DNA of Cancer Cells: A Photodynamic Therapy Study. Arch Cancer Res 4: 1 .

107. A Heidari (2016) Bio spectroscopic Study on Multi-Component Reactions (MCRs) in Two A- Type and B-Type Conformations of Nucleic Acids to Determine Ligand Binding Modes, Binding Constant and Stability of Nucleic Acids in Cadmium Oxide (CdO) NanoparticlesNucleic Acids Complexes as Anti-Cancer Drugs. Arch Cancer Res 4: 2.

108. A Heidari (2016) Simulation of Temperature Distribution of DNA/RNA of Human Cancer Cells Using Time-Dependent Bio-Heat Equation and Nd: YAG Lasers. Arch Cancer Res 4: 2

109. A Heidari (2016) Quantitative Structure-Activity Relationship (QSAR) Approximation for Cadmium Oxide (CdO) and Rhodium (III) Oxide (Rh203) Nanoparticles as Anti-Cancer Drugs for the Catalytic Formation of Proviral DNA from Viral RNA Using Multiple Linear and Non- Linear Correlation Approach. Ann Clin Lab Res 4: 1.

110. A Heidari (2016) Biomedical Study of Cancer Cells DNA Therapy Using Laser Irradiations at Presence of Intelligent Nanoparticles. J Biomedical Sci 5: 2 .
111. A Heidari (2016) Measurement the Amount of Vitamin D2 (Ergocalciferol), Vitamin D3 (Cholecalciferol) and Absorbable Calcium $\left(\mathrm{Ca}^{2+}\right)$, Iron (II) $\left(\mathrm{Fe}^{2+}\right)$, Magnesium $\left(\mathrm{Mg}^{2+}\right)$, Phosphate $\left(\mathrm{PO}^{4-}\right)$ and Zinc $\left(\mathrm{Zn}^{2+}\right)$ in Apricot Using High-Performance Liquid Chromatography (HPLC) and Spectroscopic Techniques. J Biom Biostat 7: 292.

112. A Heidari (2016) Spectroscopy and Quantum Mechanics of the Helium Dimer $\left(\mathrm{He}^{2+}\right)$, Neon Dimer $\left(\mathrm{Ne}^{2+}\right)$, Argon Dimer $\left(\mathrm{Ar}^{2+}\right)$, Krypton Dimer $\left(\mathrm{Kr}^{2+}\right)$, Xenon Dimer $\left(\mathrm{Xe}^{2+}\right)$, Radon Dimer $\left(\mathrm{Rn}^{2+}\right)$ and Ununoctium Dimer $\left(\mathrm{Uuo}^{2+}\right)$ Molecular Cations. Chem Sci J 7: e112.

113. A Heidari (2016) Human Toxicity Photodynamic Therapy Studies on DNA/RNA Complexes as a Promising New Sensitizer for the Treatment of Malignant Tumors Using Bio-Spectroscopic Techniques. J Drug Metab Toxicol 7: 2.

114. A Heidari (2016) Novel and Stable Modifications of Intelligent Cadmium Oxide (CdO) Nanoparticles as Anti-Cancer Drug in Formation of Nucleic Acids Complexes for Human Cancer Cells' Treatment. Biochem Pharmacol (Los Angel) 5: 3

115. A Heidari (2016) A Combined Computational and QM/MM Molecular Dynamics Study on Boron Nitride Nanotubes (BNNTs), Amorphous Boron Nitride Nanotubes (a-BNNTs) and Hexagonal Boron Nitride Nanotubes (h-BNNTs) as Hydrogen Storage. Struct Chem Crystallogr Commun 2: 1 .

116. A Heidari (2016) Pharmaceutical and Analytical Chemistry Study of Cadmium Oxide (CdO) Nanoparticles Synthesis Methods and Properties as Anti-Cancer Drug and its Effect on Human Cancer Cells. Pharm Anal Chem Open Access 2: 2.

117. A Heidari (2016) A Chemotherapeutic and Biospectroscopic Investigation of the Interaction of Double-Standard DNA/RNABinding Molecules with Cadmium Oxide (CdO) and Rhodium (III) Oxide (Rh203) Nanoparticles as Anti-Cancer Drugs for Cancer Cells' Treatment. Chemo Open Access 5: 2.

118. A Heidari (2016) Pharmacokinetics and Experimental Therapeutic Study of DNA and Other Biomolecules Using Lasers: Advantages and Applications. J Pharmacokinet Exp Ther 1: e005.

119. A Heidari (2016) Determination of Ratio and Stability Constant of DNA/RNA in Human Cancer Cells and Cadmium Oxide (CdO) Nanoparticles Complexes Using Analytical Electrochemical and Spectroscopic Techniques. Insights Anal Electrochem 2: 1.

120. A Heidari (2016) Discriminate between Antibacterial and NonAntibacterial Drugs Artificial Neutral Networks of a Multilayer Perceptron (MLP) Type Using a Set of Topological Descriptors. J Heavy Met Toxicity Dis 1: 2.

121. A Heidari (2016) Combined Theoretical and Computational Study of the Belousov-Zhabotinsky Chaotic Reaction and Curtius Rearrangement for Synthesis of Mechlorethamine, Cisplatin, Streptozotocin, Cyclophosphamide, Melphalan, Busulphan and BCNU as Anti-Cancer Drugs. Insights Med Phys 1: 2.

122. A Heidari (2016) A Translational Biomedical Approach to Structural Arrangement of Amino Acids' Complexes: A Combined Theoretical and Computational Study. Transl Biomed 7: 2.

123. A Heidari (2016) Ab Initio and Density Functional Theory (DFT) Studies of Dynamic NMR Shielding Tensors and Vibrational Frequencies of DNA/RNA and Cadmium Oxide (CdO) Nanoparticles Complexes in Human Cancer Cells. J Nanomedine Biotherapeutic Discov 6: 2.

124. A Heidari (2016) Molecular Dynamics and Monte-Carlo Simulations for Replacement Sugars in Insulin Resistance, Obesity, LDL Cholesterol, Triglycerides, Metabolic Syndrome, Type 2 Diabetes and Cardiovascular Disease: A Glycobiological Study. J Glycobiol 5: 1.

125. A Heidari (2016) Synthesis and Study of 5-[(Phenylsulfonyl)Amino]1,3,4-Thiadiazole-2- Sulfonamide as Potential Anti-Pertussis Drug Using Chromatography and Spectroscopy Techniques. Transl Med (Sunnyvale) 6: e138. 
126. A Heidari (2016) Nitrogen, Oxygen, Phosphorus and Sulphur Heterocyclic Anti-Cancer Nano Drugs Separation in the Supercritical Fluid of Ozone (03) Using Soave-Redlich-Kwong (SRK) and PangRobinson (PR) Equations. Electronic J Biol 12: 3.

127. A Heidari (2016) An Analytical and Computational Infrared Spectroscopic Review of Vibrational Modes in Nucleic Acids", Austin J Anal Pharm Chem 3 (1): 1058.

128. A Heidari, C Brown (2016) Phase, Composition and Morphology Study and Analysis of Os- Pd/HfC Nanocomposites. Nano Res Appl 2: 1.

129. A Heidari, C Brown (2016) Vibrational Spectroscopic Study of Intensities and Shifts of Symmetric Vibration Modes of Ozone Diluted by Cumene. International Journal of Advanced Chemistry 4(1): 5-9.

130. A Heidari (2016) Study of the Role of Anti-Cancer Molecules with Different Sizes for Decreasing Corresponding Bulk Tumor Multiple Organs or Tissues. Arch Can Res 4: 2.

131. A Heidari (2016) Genomics and Proteomics Studies of Zolpidem, Necopidem, Alpidem, Saripidem, Miroprofen, Zolimidine, Olprinone and Abafungin as Anti-Tumor, Peptide Antibiotics, Antiviral and Central Nervous System (CNS) Drugs. J Data Mining Genomics \& Proteomics 7:3.

132. A Heidari (2016) Pharmacogenomics and Pharmacoproteomics Studies of Phosphodiesterase- 5 (PDE5) Inhibitors and Paclitaxel Albumin-Stabilized Nanoparticles as Sandwiched Anti- Cancer Nano Drugs between Two DNA/RNA Molecules of Human Cancer Cells. J Pharmacogenomics Pharmacoproteomics 7: e153.

133. A Heidari (2016) Biotranslational Medical and Biospectroscopic Studies of Cadmium Oxide (CdO) Nanoparticles-DNA/RNA Straight and Cycle Chain Complexes as Potent Anti-Viral, Anti-Tumor and AntiMicrobial Drugs: A Clinical Approach. Transl Biomed 7: 2.

134. A Heidari (2016) A Comparative Study on Simultaneous Determination and Separation of Adsorbed Cadmium Oxide (CdO) Nanoparticles on DNA/RNA of Human Cancer Cells Using Biospectroscopic Techniques and Dielectrophoresis (DEP) Method. Arch Can Res 4: 2.

135. A Heidari (2016) Cheminformatics and System Chemistry of Cisplatin Carboplatin, Nedaplatin, Oxaliplatin, Heptaplatin and Lobaplatin as Anti-Cancer Nano Drugs: A Combined Computational and Experimental Study. J Inform Data Min 1: 3.

136. A Heidari (2016) Linear and Non-Linear Quantitative Structure-AntiCancer-Activity Relationship (QSACAR) Study of Hydrous Ruthenium (IV) Oxide $\left(\mathrm{RuO}_{2}\right)$ Nanoparticles as Non- Nucleoside Reverse Transcriptase Inhibitors (NNRTIs) and Anti-Cancer Nano Drugs. Integr Oncol 5: e110.

137. A Heidari (2016) Synthesis, Characterization and Biospectroscopic Studies of Cadmium Oxide (CdO) Nanoparticles-Nucleic Acids Complexes Absence of Soluble Polymer as a Protective Agent Using Nucleic Acids Condensation and Solution Reduction Method. J Nanosci Curr Res 1: e101.

138. A Heidari (2016) Coplanarity and Collinearity of 4'-Dinonyl-2,2'Bithiazole in One Domain of Bleomycin and Pingyangmycin to be Responsible for Binding of Cadmium Oxide (CdO) Nanoparticles to DNA/RNA Bidentate Ligands as Anti-Tumor Nano Drug. Int J Drug Dev \& Res 8: 007-008.

139. A Heidari (2016) A Pharmacovigilance Study on Linear and Non-Linear Quantitative Structure (Chromatographic) Retention Relationships (QSRR) Models for the Prediction of Retention Time of Anti-Cancer Nano Drugs under Synchrotron Radiations. J Pharmacovigil 4: e161.

140. A Heidari (2016) Nanotechnology in Preparation of Semipermeable Polymers. J Adv Chem Eng 6: 157.

141. A Heidari (2016) A Gastrointestinal Study on Linear and Non-Linear Quantitative Structure (Chromatographic) Retention Relationships (QSRR) Models for Analysis 5-Aminosalicylates Nano Particles as Digestive System Nano Drugs under Synchrotron Radiations. J Gastrointest Dig Syst 6: e119.
142. A Heidari (2016) DNA/RNA Fragmentation and Cytolysis in Human Cancer Cells Treated with Diphthamide Nano Particles Derivatives. Biomedical Data Mining 5: e102.

143. A Heidari (2016) A Successful Strategy for the Prediction of Solubility in the Construction of Quantitative Structure-Activity Relationship (QSAR) and Quantitative Structure-Property Relationship (QSPR) under Synchrotron Radiations Using Genetic Function Approximation (GFA) Algorithm. J Mol Biol Biotechnol 1: 1.

144. A Heidari (2016) Computational Study on Molecular Structures of C20, C60, C240, C540, C960, C2160 and C3840 Fullerene Nano Molecules under Synchrotron Radiations Using Fuzzy Logic. J Material Sci Eng 5: 282.

145. A Heidari (2016) Graph Theoretical Analysis of Zigzag Polyhexamethylene Biguanide, Polyhexamethylene Adipamide, Polyhexamethylene Biguanide Gauze and Polyhexamethylene Biguanide Hydrochloride (PHMB) Boron Nitride Nanotubes (BNNTs), Amorphous Boron Nitride Nanotubes (a-BNNTs) and Hexagonal Boron Nitride Nanotubes (h-BNNTs). J Appl Computat Math 5: e143.

146. A Heidari (2016) The Impact of High-Resolution Imaging on Diagnosis. Int J Clin Med Imaging 3: 1000e101.

147. A Heidari (2016) A Comparative Study of Conformational Behavior of Isotretinoin (13-Cis Retinoic Acid) and Tretinoin (All-Trans Retinoic Acid (ATRA)) Nano Particles as Anti-Cancer Nano Drugs under Synchrotron Radiations Using Hartree-Fock (HF) and Density Functional Theory (DFT) Methods. Insights in Biomed 1: 2.

148. A Heidari (2016) Advances in Logic, Operations and Computational Mathematics. J Appl Computat Math 5: e144.

149. A Heidari (2016) Mathematical Equations in Predicting Physical Behavior. J Appl Computat Math 5: e145.

150. A Heidari (2016) Chemotherapy a Last Resort for Cancer Treatment. Chemo Open Access 5: 4.

151. A Heidari (2016) Separation and Pre-Concentration of Metal CationsDNA/RNA Chelates Using Molecular Beam Mass Spectrometry with Tunable Vacuum Ultraviolet (VUV) Synchrotron Radiation and Various Analytical Methods. Mass Spectrom Purif Tech 2: e101.

152. A Heidari (2016) Yoctosecond Quantitative Structure-Activity Relationship (QSAR) and Quantitative Structure-Property Relationship (QSPR) under Synchrotron Radiations Studies for Prediction of Solubility of Anti-Cancer Nano Drugs in Aqueous Solutions Using Genetic Function Approximation (GFA) Algorithm. Journal of Pharmacy and Pharmaceutical Research 1(6).

153. A Heidari (2016) Cancer Risk Prediction and Assessment in Human Cells under Synchrotron Radiations Using Quantitative Structure Activity Relationship (QSAR) and Quantitative Structure Properties Relationship (QSPR) Studies. International Journal of Clinical \& Medical Imaging 3(10): 516.

154. A Heidari (2016) A Novel Approach to Biology. Electronic J Biol 12: 4.

155. A Heidari (2016) Innovative Biomedical Equipment's for Diagnosis and Treatment. J Bioengineer \& Biomedical Sci 6: 2.

156. A Heidari (2016) Integrating Precision Cancer Medicine into Healthcare, Medicare Reimbursement Changes and the Practice of Oncology: Trends in Oncology Medicine and Practices. J Oncol Med \& Pract 1:2.

157. A Heidari (2016) Promoting Convergence in Biomedical and Biomaterials Sciences and Silk Proteins for Biomedical and Biomaterials Applications: An Introduction to Materials in Medicine and Bioengineering Perspectives. J Bioengineer \& Biomedical Sci 6: 3.

158. A Heidari (2017) X-Ray Fluorescence and X-Ray Diffraction Analysis on Discrete Element Modeling of Nano Powder Metallurgy Processes in Optimal Container Design. J Powder Metall Min 6: 1. 
159. A Heidari (2017) Biomolecular Spectroscopy and Dynamics of NanoSized Molecules and Clusters as Cross-Linking-Induced Anti-Cancer and Immune-Oncology Nano Drugs Delivery in DNA/RNA of Human Cancer Cells' Membranes under Synchrotron Radiations: A PayloadBased Perspective. Archives in Chemical Research Res 1: 2.

160. A Heidari (2017) Deficiencies in Repair of Double-Standard DNA/RNABinding Molecules Identified in Many Types of Solid and Liquid Tumors Oncology in Human Body for Advancing Cancer Immunotherapy Using Computer Simulations and Data Analysis: Number of Mutations in a Synchronous Tumor Varies by Age and Type of Synchronous Cancer. Journal of Applied Bioinformatics \&Computational Biology 6(1)

161. A Heidari (2017) Electronic Coupling among the Five Nanomolecules Shuts Down Quantum Tunneling in the Presence and Absence of an Applied Magnetic Field for Indication of the Dimer or other Provide Different Influences on the Magnetic Behavior of Single Molecular Magnets (SMMs) as Qubits for Quantum Computing. Global Journal of Research and Review 4: 2.

162. A Heidari (2017) Polymorphism in Nano-Sized Graphene LigandInduced Transformation of Au38-xAgx/xCux(SPh-tBu)24 to Au36$\mathrm{xAgx} / \mathrm{xCux}(\mathrm{SPh}-\mathrm{tBu}) 24$ ( $\mathrm{x}=1$ 1-12) Nanomolecules for Synthesis of Au144-xAgx/xCux[(SR)60, (SC4)60, (SC6)60, (SC12)60, (PET)60, (p-MBA)60, (F)60, (Cl)60, (Br)60, (I)60, (At)60, (Uus)60 and (SC6H13)60] Nano Clusters as Anti-Cancer Nano Drugs. Journal of Nanomaterials \& Molecular Nanotechnology 6: 3.

163. A Heidari (2017) Biomedical Resource Oncology and Data Mining to Enable Resource Discovery in Medical, Medicinal, Clinical, Pharmaceutical, Chemical and Translational Research and Their Applications in Cancer Research. International Journal of Biomedical Data Mining 692): 103.

164. A Heidari (2017) Study of Synthesis, Pharmacokinetics, Pharmacodynamics, Dosing, Stability, Safety and Efficacy of Olympiadane Nanomolecules as Agent for Cancer Enzymotherapy, Immunotherapy, Chemotherapy, Radiotherapy, Hormone Therapy and Targeted Therapy under Synchrotorn Radiation. Journal of Developing Drugs 6(2): 154.

165. A Heidari (2017) A Novel Approach to Future Horizon of Top Seven Biomedical Research Topics to Watch in 2017: Alzheimer's, Ebola, Hypersomnia, Human Immunodeficiency Virus (HIV), Tuberculosis (TB), Microbiome/Antibiotic Resistance and Endovascular Stroke. J Bioengineer \& Biomedical Sci 7: e127.

166. A Heidari (2017) Opinion on Computational Fluid Dynamics (CFD) Technique. Fluid Mech Open Acc 4: 157.

167. A Heidari (2017) Concurrent Diagnosis of Oncology Influence Outcomes in Emergency General Surgery for Colorectal Cancer and Multiple Sclerosis (MS) Treatment Using Magnetic Resonance Imaging (MRI) and Au329(SR)84, Au329-xAgx(SR)84, Au144(SR)60, Au68(SR)36, Au30(SR)18,Au102(SPh)44, Au38(SPh)24 Au38(SC2H4Ph)24,Au21S(SAdm)15, Au36(pMBA)24 and Au25(pMBA)18 Nano Clusters. J Surgery Emerg Med1: 21.

168. A Heidari (2017) Developmental Cell Biology in Adult Stem Cells Death and Autophagy to Trigger a Preventive Allergic Reaction to Common Airborne Allergens under Synchrotron Radiation Using Nanotechnology for Therapeutic Goals in Particular Allergy Shots (Immunotherapy). Cell Biology: Research \& Therapy 6: 1.

169. A Heidari (2017) hanging Metal Powder Characteristics for Elimination of the Heavy Metals Toxicity and Diseases in Disruption of Extracellular Matrix (ECM) Proteins Adjustment in Cancer Metastases Induced by Osteosarcoma, Chondrosarcoma, Carcinoid, Carcinoma, Ewing's Sarcoma, Fibrosarcoma and Secondary Hematopoietic Solid or Soft Tissue Tumors. J Powder Metall Min 6: 170

170. A Heidari (2017) Nanomedicine-Based Combination Anti-Cancer Therapy between Nucleic Acids and Anti-Cancer Nano Drugs in Covalent Nano Drugs Delivery Systems for Selective Imaging and Treatment of Human Brain Tumors Using Hyaluronic Acid, Alguronic
Acid and Sodium Hyaluronate as Anti-Cancer Nano Drugs and Nucleic Acids Delivery under Synchrotron Radiation. Am J Drug Deliv 5: 2.

171. A Heidari (2017) Clinical Trials of Dendritic Cell Therapies for Cancer Exposing Vulnerabilities in Human Cancer Cells' Metabolism and Metabolomics: New Discoveries, Unique Features Inform New Therapeutic Opportunities, Biotech's Bumpy Road to the Market and Elucidating the Biochemical Programs that Support Cancer Initiation and Progression. J Biol Med Science 1: e103,

172. A Heidari (2017) he Design Graphene-Based Nanosheets as a New Nanomaterial in Anti- Cancer Therapy and Delivery of Chemotherapeutics and Biological Nano Drugs for Liposomal AntiCancer Nano Drugs and Gene Delivery. British Biomedical Bulletin 5: 305.

173. A Heidari (2017) Integrative Approach to Biological Networks for Emerging Roles of Proteomics, Genomics and Transcriptomics in the Discovery and Validation of Human Colorectal Cancer Biomarkers from DNA/RNA Sequencing Data under Synchrotron Radiation. Transcriptomics: Open Access 5(2):117.

174. A Heidari (2017) Elimination of the Heavy Metals Toxicity and Diseases in Disruption of Extracellular Matrix (ECM) Proteins and Cell Adhesion Intelligent Nanomolecules Adjustment in Cancer Metastases Using Metalloenzymes and under Synchrotron Radiation. Lett Health Biol Sci 2(2): 1-4.

175. A Heidari (2017) Treatment of Breast Cancer Brain Metastases through a Targeted Nanomolecule Drug Delivery System Based on Dopamine Functionalized Multi-Wall Carbon Nanotubes (MWCNTs) Coated with Nano Graphene Oxide (GO) and Protonated Polyaniline (PANI) in Situ During the Polymerization of Aniline Autogenic Nanoparticles for the Delivery of Anti-Cancer Nano Drugs under Synchrotron Radiation. Br J Res 4(3): 16.

176. A Heidari (2017) Sedative, Analgesic and Ultrasound-Mediated Gastrointestinal Nano Drugs Delivery for Gastrointestinal Endoscopic Procedure, Nano Drug-Induced Gastrointestinal Disorders and Nano Drug Treatment of Gastric Acidity. Research and Reports in Gastroenterology 1: 1

177. A Heidari (2017) Synthesis, Pharmacokinetics, Pharmacodynamics, Dosing, Stability, Safety and Efficacy of Orphan Nano Drugs to Treat High Cholesterol and Related Conditions and to Prevent Cardiovascular Disease under Synchrotron Radiation. Journal of Pharmaceutical Sciences \& Emerging Drugs 5: 1.

178. A Heidari (2017) Non-Linear Compact Proton Synchrotrons to Improve Human Cancer Cells and Tissues Treatments and Diagnostics through Particle Therapy Accelerators with Monochromatic Microbeams. J Cell Biol Mol Sci 2(1): 1-5.

179. A Heidari (2017) Design of Targeted Metal Chelation Therapeutics Nanocapsules as Colloidal Carriers and Blood-Brain Barrier (BBB) Translocation to Targeted Deliver Anti-Cancer Nano Drugs into the Human Brain to Treat Alzheimer's Disease under Synchrotron Radiation. J Nanotechnol Material Sci 4(2): 1-5.

180. R Gobato, A Heidari, (2017) Calculations Using Quantum Chemistry for Inorganic Molecule Simulation BeLi2SeSi", Science Journal of Analytical Chemistry 5(6): 76-85

181. A Heidari (2017) Different High-Resolution Simulations of Medical, Medicinal, Clinical, Pharmaceutical and Therapeutics Oncology of Human Lung Cancer Translational Anti-Cancer Nano Drugs Delivery Treatment Process under Synchrotron and X-Ray Radiations. Journal of Medical Oncology 1(1).

182. A Heidari (2017) A Modern Ethnomedicinal Technique for Transformation, Prevention and Treatment of Human Malignant Gliomas Tumors into Human Benign Gliomas Tumors under Synchrotron Radiation. American Journal of Ethnomedicine 4(1): 10.

183. A Heidari (2017) Active Targeted Nanoparticles for Anti-Cancer Nano Drugs Delivery across the Blood-Brain Barrier for Human Brain Cancer Treatment, Multiple Sclerosis (MS) and Alzheimer's 
Diseases Using Chemical Modifications of Anti-Cancer Nano Drugs or Drug- Nanoparticles through Zika Virus (ZIKV) Nanocarriers under Synchrotron Radiation. Journal of Medicinal Chemistry \& Toxicology 2(3): $1-5$.

184. A Heidari (2017) Investigation of Medical, Medicinal, Clinical and Pharmaceutical Applications of Estradiol, Mestranol (Norlutin), Norethindrone (NET), Norethisterone Acetate (NETA), Norethisterone Enanthate (NETE) and Testosterone Nanoparticles as Biological Imaging, Cell Labeling, Anti-Microbial Agents and Anti-Cancer Nano Drugs in Nanomedicines Based Drug Delivery Systems for Anti-Cancer Targeting and Treatment. Parana Journal of Science and Education (PJSE) 3(4): 10-19.

185. A Heidari (2017) A Comparative Computational and Experimental Study on Different Vibrational Biospectroscopy Methods, Techniques and Applications for Human Cancer Cells in Tumor Tissues Simulation, Modeling, Research, Diagnosis and Treatment. Open Journal of Analytical and Bioanalytical Chemistry 1(1): 14-20.

186. A Heidari (2017) Combination of DNA/RNA Ligands and Linear/ Non-Linear Visible- Synchrotron Radiation-Driven N-Doped Ordered Mesoporous Cadmium Oxide (CdO) Nanoparticles Photocatalysts Channels Resulted in an Interesting Synergistic Effect Enhancing Catalytic Anti-Cancer Activity. Enz Eng 6: 1.

187. A Heidari (2017) Modern Approaches in Designing Ferritin, Ferritin Light Chain, Transferrin, Beta-2 Transferrin and Bacterioferritin-Based Anti-Cancer Nano Drugs Encapsulating Nanosphere as DNA-Binding Proteins from Starved Cells (DPS). Mod Appro Drug Des 1(1): 1-5.

188. A Heidari (2017) Potency of Human Interferon $\beta-1 \mathrm{a}$ and Human Interferon $\beta-1 b$ in Enzymotherapy, Immunotherapy, Chemotherapy, Radiotherapy, Hormone Therapy and Targeted Therapy of Encephalomyelitis Disseminate/Multiple Sclerosis (MS) and Hepatitis A, B, C, D, E, F and G Virus Enter and Targets Liver Cells. Journal of Proteomics \& Enzymology 6: 1 .

189. A Heidari (2017) Transport Therapeutic Active Targeting of Human Brain Tumors Enable Anti-Cancer Nanodrugs Delivery across the Blood-Brain Barrier (BBB) to Treat Brain Diseases Using Nanoparticles and Nanocarriers under Synchrotron Radiation. J Pharm Pharmaceutics 4(2): 1-5.

190. A.Heidari, C.Brown, (2017) Combinatorial Therapeutic Approaches to DNA/RNA and Benzylpenicillin (Penicillin G), Fluoxetine Hydrochloride (Prozac and Sarafem), Propofol (Diprivan), Acetylsalicylic Acid (ASA) (Aspirin), Naproxen Sodium (Aleve and Naprosyn) and Dextromethamphetamine Nanocapsules with Surface Conjugated DNA/RNA to Targeted Nano Drugs for Enhanced Anti-Cancer Efficacy and Targeted Cancer Therapy Using Nano Drugs Delivery Systems. Annals of Advances in Chemistry 1(2): 61-69.

191. A.Heidari (2017) High-Resolution Simulations of Human Brain Cancer Translational Nano Drugs Delivery Treatment Process under Synchrotron Radiation. J Transl Res 1(1): 1-3.

192. A Heidari (2017) Investigation of Anti-Cancer Nano Drugs' Effects' Trend on Human Pancreas Cancer Cells and Tissues Prevention, Diagnosis and Treatment Process under Synchrotron and X-Ray Radiations with the Passage of Time Using Mathematica. Current Trends Anal Bioanal Chem 1(1): 36-41.

193. A.Heidari (2017) Pros and Cons Controversy on Molecular Imaging and Dynamics of Double- Standard DNA/RNA of Human Preserving Stem Cells-Binding Nano Molecules with Androgens/Anabolic Steroids (AAS) or Testosterone Derivatives through Tracking of Helium-4 Nucleus (Alpha Particle) Using Synchrotron Radiation. Archives of Biotechnology and Biomedicine 1(1): 67-100.

194. A Heidari (2017) Visualizing Metabolic Changes in Probing Human Cancer Cells and Tissues Metabolism Using Vivo 1H or Proton NMR, 13C NMR, 15N NMR and 31P NMR Spectroscopy and Self-Organizing Maps under Synchrotron Radiation. SOJ Materials Science \& Engineering 5(2): 1-6.
195. A Heidari (2017) Cavity Ring-Down Spectroscopy (CRDS), Circular Dichroism Spectroscopy, Cold Vapour Atomic Fluorescence Spectroscopy and Correlation Spectroscopy Comparative Study on Malignant and Benign Human Cancer Cells and Tissues with the Passage of Time under Synchrotron Radiation. Enliven: Challenges Cancer Detection Therapy 4(2): 1.

196. A Heidari (2017) Laser Spectroscopy, Laser-Induced Breakdown Spectroscopy and Laser- Induced Plasma Spectroscopy Comparative Study on Malignant and Benign Human Cancer Cells and Tissues with the Passage of Time under Synchrotron Radiation. International Journal of Hepatology \& Gastroenterology 3(4): 79-84.

197. A Heidari (2017) Time-Resolved Spectroscopy and Time-Stretch Spectroscopy Comparative Study on Malignant and Benign Human Cancer Cells and Tissues with the Passage of Time under Synchrotron Radiation. Enliven: Pharmacovigilance and Drug Safety 4(2): e001.

198. A Heidari (2017) Overview of the Role of Vitamins in Reducing Negative Effect of Decapeptyl (Triptorelin Acetate or Pamoate Salts) on Prostate Cancer Cells and Tissues in Prostate Cancer Treatment Process through Transformation of Malignant Prostate Tumors into Benign Prostate Tumors under Synchrotron Radiation. Open J Anal Bioanal Chem 1(1): 21-26.

199. A Heidari (2017) Electron Phenomenological Spectroscopy, Electron Paramagnetic Resonance (EPR) Spectroscopy and Electron Spin Resonance (ESR) Spectroscopy Comparative Study on Malignant and Benign Human Cancer Cells and Tissues with the Passage of Time under Synchrotron Radiation. Austin J Anal Pharm Chem 4(3): 1091.

200. A Heidari (2017) Therapeutic Nanomedicine Different HighResolution Experimental Images and Computational Simulations for Human Brain Cancer Cells and Tissues Using Nanocarriers Deliver DNA/RNA to Brain Tumors under Synchrotron Radiation with the Passage of Time Using Mathematica and MATLAB. Madridge Journal of Nanotechnology \& NanoscienceSci 2(2): 77-83.

201. A Heidari (2017) "A Consensus and Prospective Study on Restoring Cadmium Oxide (CdO) Nanoparticles Sensitivity in Recurrent Ovarian Cancer by Extending the Cadmium Oxide (CdO) Nanoparticles-Free Interval Using Synchrotron Radiation Therapy as Antibody-Drug Conjugate for the Treatment of Limited-Stage Small Cell Diverse Epithelial Cancers". Cancer Clin Res Rep 1: 2.

202. A Heidari (2017) "A Novel and Modern Experimental Imaging and Spectroscopy Comparative Study on Malignant and Benign Human Cancer Cells and Tissues with the Passage of Time under White Synchrotron Radiation". Cancer Sci Res Open Access 4(2): 1-8.

203. A Heidari (2017) “Different High-Resolution Simulations of Medical, Medicinal, Clinical, Pharmaceutical and Therapeutics Oncology of Human Breast Cancer Translational Nano Drugs Delivery Treatment Process under Synchrotron and X-Ray Radiations". J Oral Cancer Res 1(1): 12-17.

204. A Heidari (2017) "Vibrational Decihertz (dHz), Centihertz (cHz), Millihertz (mHz), Microhertz ( $\mu \mathrm{Hz})$, Nanohertz (nHz), Picohertz (pHz), Femtohertz (fHz), Attohertz (aHz), Zeptohertz (zHz) and Yoctohertz (yHz) Imaging and Spectroscopy Comparative Study on Malignant and Benign Human Cancer Cells and Tissues under Synchrotron Radiation". International Journal of Biomedicine 7(4): 335-340.

205. A Heidari (2017) “Force Spectroscopy and Fluorescence Spectroscopy Comparative Study on Malignant and Benign Human Cancer Cells and Tissues with the Passage of Time under Synchrotron Radiation". EC Cancer 2(5): 239-246.

206. A Heidari (2017) "Photoacoustic Spectroscopy, Photoemission Spectroscopy and Photothermal Spectroscopy Comparative Study on Malignant and Benign Human Cancer Cells and Tissues with the Passage of Time under Synchrotron Radiation". BAOJ Cancer Res Ther 3(3) 45-52.

207. A Heidari (2017) “J-Spectroscopy, Exchange Spectroscopy (EXSY), Nuclear Overhauser Effect Spectroscopy (NOESY) and Total Correlation 
Spectroscopy (TOCSY) Comparative Study on Malignant and Benign Human Cancer Cells and Tissues under Synchrotron Radiation". EMS Eng Sci J 1(2): 006-013.

208. A Heidari (2017) "Neutron Spin Echo Spectroscopy and Spin Noise Spectroscopy Comparative Study on Malignant and Benign Human Cancer Cells and Tissues with the Passage of Time under Synchrotron Radiation". Int J Biopharm Sci 1(1): 103-107.

209. A Heidari (2017) “Vibrational Decahertz (daHz), Hectohertz (hHz), Kilohertz (kHz), Megahertz (MHz), Gigahertz (GHz), Terahertz (THz), Petahertz (PHz), Exahertz (EHz), Zettahertz $(\mathrm{ZHz})$ and Yottahertz (YHz) Imaging and Spectroscopy Comparative Study on Malignant and Benign Human Cancer Cells and Tissues under Synchrotron Radiation". Madridge J Anal Sci Instrum 2(1): 41-46.

210. A Heidari (2018) “Two-Dimensional Infrared Correlation Spectroscopy, Linear Two- Dimensional Infrared Spectroscopy and Non-Linear TwoDimensional Infrared Spectroscopy Comparative Study on Malignant and Benign Human Cancer Cells and Tissues under Synchrotron Radiation with the Passage of Time". J Mater Sci Nanotechnol 6(1): 101

211. A Heidari (2018) "Fourier Transform Infrared (FTIR) Spectroscopy, Near-Infrared Spectroscopy (NIRS) and Mid-Infrared Spectroscopy (MIRS) Comparative Study on Malignant and Benign Human Cancer Cells and Tissues under Synchrotron Radiation with the Passage of Time". Int J Nanotechnol Nanomed 3(1): 1-6.

212. A Heidari (2018) "Infrared Photo Dissociation Spectroscopy and Infrared Correlation Table Spectroscopy Comparative Study on Malignant and Benign Human Cancer Cells and Tissues under Synchrotron Radiation with the Passage of Time". Austin Pharmaco Pharm 3(1): 1011.

213. A Heidari (2018) “Novel and Transcendental Prevention, Diagnosis and Treatment Strategies for Investigation of Interaction among Human Blood Cancer Cells, Tissues, Tumors and Metastases with Synchrotron Radiation under Anti-Cancer Nano Drugs Delivery Efficacy Using MATLAB Modeling and Simulation". Madridge J Nov Drug Res 1(1) 18-24.

214. A Heidari (2018) “Comparative Study on Malignant and Benign Human Cancer Cells and Tissues with the Passage of Time under Synchrotron Radiation". Open Access J Trans Med Res 2(1): 4-9.

215. MRR Gobato, R Gobato, A Heidari (2018) “Planting of Jaboticaba Trees for Landscape Repair of Degraded Area”, Landscape Architecture and Regional Planning 3(1): 1-9.

216. A Heidari (2018) "Fluorescence Spectroscopy, Phosphorescence Spectroscopy and Luminescence Spectroscopy Comparative Study on Malignant and Benign Human Cancer Cells and Tissues under Synchrotron Radiation with the Passage of Time". SM J Clin Med Imaging 4(1): 1018.

217. A Heidari (2018) "Nuclear Inelastic Scattering Spectroscopy (NISS) and Nuclear Inelastic Absorption Spectroscopy (NIAS) Comparative Study on Malignant and Benign Human Cancer Cells and Tissues under Synchrotron Radiation". Int J Pharm Sci 2(1): 1-14.

218. A Heidari (2018) "X-Ray Diffraction (XRD), Powder X-Ray Diffraction (PXRD) and Energy- Dispersive X-Ray Diffraction (EDXRD) Comparative Study on Malignant and Benign Human Cancer Cells and Tissues under Synchrotron Radiation". J Oncol Res 2(1): 1-14.

219. A Heidari (2018) “Correlation Two-Dimensional Nuclear Magnetic Resonance (NMR) (2D- NMR) (COSY) Imaging and Spectroscopy Comparative Study on Malignant and Benign Human Cancer Cells and Tissues under Synchrotron Radiation". EMS Can Sci 1(1); 001.

220. A Heidari (2018) “Thermal Spectroscopy, Photothermal Spectroscopy, Thermal Microspectroscopy, Photothermal Microspectroscopy, Thermal Macrospectroscopy and Photothermal Macrospectroscopy Comparative Study on Malignant and Benign Human Cancer Cells and Tissues with the Passage of Time under Synchrotron Radiation". SM J Biometrics Biostat 3(1): 1024.
221. A Heidari (2018) "A Modern and Comprehensive Experimental Biospectroscopic Comparative Study on Human Common Cancers' Cells, Tissues and Tumors before and after Synchrotron Radiation Therapy". Open Acc J Oncol Med 1(1).

222. A Heidari (2018) "Heteronuclear Correlation Experiments such as Heteronuclear Single- Quantum Correlation Spectroscopy (HSQC), Heteronuclear Multiple-Quantum Correlation Spectroscopy (HMQC) and Heteronuclear Multiple-Bond Correlation Spectroscopy (HMBC) Comparative Study on Malignant and Benign Human Endocrinology and Thyroid Cancer Cells and Tissues under Synchrotron Radiation". J Endocrinol Thyroid Res 3 (1): 001-007.

223. A Heidari (2018) "Nuclear Resonance Vibrational Spectroscopy (NRVS), Nuclear Inelastic Scattering Spectroscopy (NISS), Nuclear Inelastic Absorption Spectroscopy (NIAS) and Nuclear Resonant Inelastic X-Ray Scattering Spectroscopy (NRIXSS) Comparative Study on Malignant and Benign Human Cancer Cells and Tissues under Synchrotron Radiation". Int J Bioorg Chem Mol Biol 6 (1e): 1-5.

224. A Heidari (2018) "A Novel and Modern Experimental Approach to Vibrational Circular Dichroism Spectroscopy and Video Spectroscopy Comparative Study on Malignant and Benign Human Cancer Cells and Tissues with the Passage of Time under White and Monochromatic Synchrotron Radiation". Glob J Endocrinol Metab 1(3): 1-6.

225. A Heidari "Pros and Cons Controversy on Heteronuclear Correlation Experiments such as Heteronuclear Single-Quantum Correlation Spectroscopy (HSQC), Heteronuclear Multiple- Quantum Correlation Spectroscopy (HMQC) and Heteronuclear Multiple-Bond Correlation Spectroscopy (HMBC) Comparative Study on Malignant and Benign Human Cancer Cells and Tissues under Synchrotron Radiation", EMS Pharma J 1(1): 002-008.

226. A Heidari (2018) "A Modern Comparative and Comprehensive Experimental Bio spectroscopic Study on Different Types of Infrared Spectroscopy of Malignant and Benign Human Cancer Cells and Tissues with the Passage of Time under Synchrotron Radiation". J Analyt Molecul Tech 3(1): 8.

227. A Heidari (2018) "Investigation of Cancer Types Using Synchrotron Technology for Proton Beam Therapy: An Experimental Biospectroscopic Comparative Study". European Modern Studies Journal 2(1) 13-29.

228. A Heidari (2018) "Saturated Spectroscopy and Unsaturated Spectroscopy Comparative Study on Malignant and Benign Human Cancer Cells and Tissues with the Passage of Time under Synchrotron Radiation". Imaging J Clin Medical Sci 5(1): 1-7.

229. A Heidari (2018) "Small-Angle Neutron Scattering (SANS) and WideAngle X-Ray Diffraction (WAXD) Comparative Study on Malignant and Benign Human Cancer Cells and Tissues under Synchrotron Radiation". Int J Bio org Chem Mol Biol 6(2e): 1-6.

230. A Heidari (2018) "Investigation of Bladder Cancer, Breast Cancer, Colorectal Cancer, Endometrial Cancer, Kidney Cancer, Leukemia, Liver, Lung Cancer, Melanoma, Non-Hodgkin Lymphoma, Pancreatic Cancer, Prostate Cancer, Thyroid Cancer and Non-Melanoma Skin Cancer Using Synchrotron Technology for Proton Beam Therapy: An Experimental Bio spectroscopic Comparative Study". Ther Res Skin Dis 1(1).

231. A Heidari (2018) "Attenuated Total Reflectance Fourier Transform Infrared (ATR-FTIR) Spectroscopy, Micro-Attenuated Total Reflectance Fourier Transform Infrared (Micro-ATR- FTIR) Spectroscopy and Macro-Attenuated Total Reflectance Fourier Transform Infrared (Macro-ATR-FTIR) Spectroscopy Comparative Study on Malignant and Benign Human Cancer Cells and Tissues under Synchrotron Radiation with the Passage of Time". International Journal of Chemistry Papers 2(1): 1-12.

232. A Heidari (2018) "Mossbauer Spectroscopy, Mossbauer Emission Spectroscopy and Mossbauer Spectroscopy Comparative Study on Malignant and Benign Human Cancer Cells and Tissues under Synchrotron Radiation". Acta Scientific Cancer Biology 2(3): 17-20. 
233. A Heidari (2018) “Comparative Study on Malignant and Benign Human Cancer Cells and Tissues under Synchrotron Radiation with the Passage of Time", Organic \& Medicinal Chem IJ 6(1): 555676.

234. A Heidari (2018) "Correlation Spectroscopy, Exclusive Correlation Spectroscopy and Total Correlation Spectroscopy Comparative Study on Malignant and Benign Human AIDS-Related Cancers Cells and Tissues with the Passage of Time under Synchrotron Radiation", Int J Bioanal Biomed 2(1): 001-007.

235. A Heidari (2018) "Biomedical Instrumentation and Applications of Bio spectroscopic Methods and Techniques in Malignant and Benign Human Cancer Cells and Tissues Studies under Synchrotron Radiation and Anti-Cancer Nano Drugs Delivery". Am J Nanotechnol Nanomed 1(1): 001-009.

236. A Heidari (2018) "Vivo ${ }^{1} \mathrm{H}$ or Proton NMR, ${ }^{13} \mathrm{C}$ NMR, ${ }^{15} \mathrm{~N}$ NMR and ${ }^{31} \mathrm{P}$ NMR Spectroscopy Comparative Study on Malignant and Benign Human Cancer Cells and Tissues under Synchrotron Radiation". Ann Biomet Bio stat 1(1): 1001

237. A Heidari (2018) “Grazing-Incidence Small-Angle Neutron Scattering (GISANS) and Grazing-Incidence X-Ray Diffraction (GIXD) Comparative Study on Malignant and Benign Human Cancer Cells, Tissues and Tumors under Synchrotron Radiation". Ann Cardiovasc Surg. 1(2): 1006.

238. A Heidari (2018) "Adsorption Isotherms and Kinetics of Multi-Walled Carbon Nanotubes (MWCNTs), Boron Nitride Nanotubes (BNNTs), Amorphous Boron Nitride Nanotubes (a- BNNTs) and Hexagonal Boron Nitride Nanotubes (h-BNNTs) for Eliminating Carcinoma, Sarcoma, Lymphoma, Leukemia, Germ Cell Tumor and Blastoma Cancer Cells and Tissues". Clin Med Rev Case Rep 5(1): 201.

239. A Heidari (2018) "Correlation Spectroscopy (COSY), Exclusive Correlation Spectroscopy (ECOSY), Total Correlation Spectroscopy (TOCSY), Incredible Natural-Abundance Double- Quantum Transfer Experiment (INADEQUATE), Heteronuclear Single-Quantum Correlation Spectroscopy (HSQC), Heteronuclear Multiple-Bond Correlation Spectroscopy (HMBC), Nuclear Over Hauser Effect Spectroscopy (NOESY) and Rotating Frame Nuclear Over Hauser Effect Spectroscopy (ROESY) Comparative Study on Malignant and Benign Human Cancer Cells and Tissues under Synchrotron Radiation". Acta Scientific Pharmaceutical Sciences 2(5): 30-35.

240. A Heidari (2018) "Small-Angle X-Ray Scattering (SAXS), Ultra-Small Angle X-Ray Scattering (USAXS), Fluctuation X-Ray Scattering (FXS) Wide-Angle X-Ray Scattering (WAXS), Grazing-Incidence Small-Angle X-Ray Scattering (GISAXS), Grazing-Incidence Wide-Angle X-Ray Scattering (GIWAXS), Small-Angle Neutron Scattering (SANS), GrazingIncidence Small-Angle Neutron Scattering (GISANS), X-Ray Diffraction (XRD), Powder X-Ray Diffraction (PXRD), Wide-Angle X-Ray Diffraction (WAXD), Grazing-Incidence X-Ray Diffraction (GIXD) and EnergyDispersive X-Ray Diffraction (EDXRD) Comparative Study on Malignant and Benign Human Cancer Cells and Tissues under Synchrotron Radiation". Oncol Res Rev 1(1): 1-10.

241. A Heidari (2018) "Pump-Probe Spectroscopy and Transient Grating Spectroscopy Comparative Study on Malignant and Benign Human Cancer Cells and Tissues with the Passage of Time under Synchrotron Radiation". Adv Material Sci Eng (2)1: 1-7.

242. A Heidari (2018) "Grazing-Incidence Small-Angle X-Ray Scattering (GISAXS) and Grazing- Incidence Wide-Angle X-Ray Scattering (GIWAXS) Comparative Study on Malignant and Benign Human Cancer Cells and Tissues under Synchrotron Radiation", Insights Pharmacol Pharm Sci 1(1): 1-8.

243. A Heidari (2018) "Acoustic Spectroscopy, Acoustic Resonance Spectroscopy and Auger Spectroscopy Comparative Study on AntiCancer Nano Drugs Delivery in Malignant and Benign Human Cancer Cells and Tissues with the Passage of Time under Synchrotron Radiation". Nanosci Technol 5(1): 1-9.

244. A Heidari (2018) "Niobium, Technetium, Ruthenium, Rhodium, Hafnium, Rhenium, Osmium and Iridium Ions Incorporation into the
Nano Polymeric Matrix (NPM) by Immersion of the Nano Polymeric Modified Electrode (NPME) as Molecular Enzymes and Drug Targets for Human Cancer Cells, Tissues and Tumors Treatment under Synchrotron and Synchrocyclotron Radiations". Nanomed Nanotechnol 3(2): 000138.

245. A Heidari (2018) "Homonuclear Correlation Experiments such as Homonuclear Single- Quantum Correlation Spectroscopy (HSQC), Homonuclear Multiple-Quantum Correlation Spectroscopy (HMQC) and Homonuclear Multiple-Bond Correlation Spectroscopy (HMBC) Comparative Study on Malignant and Benign Human Cancer Cells and Tissues under Synchrotron Radiation". Austin J Proteomics Bioinform \& Genomics 5(1): 1024.

246. A Heidari (2018) "Atomic Force Microscopy Based Infrared (AFMIR) Spectroscopy and Nuclear Resonance Vibrational Spectroscopy Comparative Study on Malignant and Benign Human Cancer Cells and Tissues under Synchrotron Radiation with the Passage of Time". J Appl Biotechnol Bioeng 5(3): 142-148.

247. A Heidari (2018) "Time-Dependent Vibrational Spectral Analysis of Malignant and Benign Human Cancer Cells and Tissues under Synchrotron Radiation". J Cancer Oncol 2(2): 000124.

248. A Heidari (2018) "Palauamine and Olympiadane Nano Molecules Incorporation into the Nano Polymeric Matrix (NPM) by Immersion of the Nano Polymeric Modified Electrode (NPME) as Molecular Enzymes and Drug Targets for Human Cancer Cells, Tissues and Tumors Treatment under Synchrotron and Synchrocyclotron Radiations". Arc Org Inorg Chem Sci 3(1).

249. R Gobato,A Heidari(2018) "Infrared Spectrum and Sites of Action of Sanguinarine by Molecular MechanicsandabinitioMethods'. International Journal of Atmosphericand OceanicSciences 2(1): 1-9.

250. A Heidari (2018) "Angelic Acid, Diabolic Acids, Draculin and Miraculin Nano Molecules Incorporation into the Nano Polymeric Matrix (NPM) by Immersion of the Nano Polymeric Modified Electrode (NPME) as Molecular Enzymes and Drug Targets for Human Cancer Cells, Tissues and Tumors Treatment Under Synchrotron and Synchrocyclotron Radiations". Med \& Analy Chem Int J 2(1): 000111.

251. A Heidari (2018) "Gamma Linolenic Methyl Ester, 5-Heptadeca5,8,11-Trienyl 1,3,4- Oxadiazole-2-Thiol, Sulphoquinovosyl Diacyl Glycerol, Ruscogenin, Nocturnoside B, Protodioscine B, Parquisoside-B, Leiocarposide, Narangenin, 7-Methoxy Hespertin, Lupeol, Rosemariquinone, Rosmanol and Rosemadiol Nano Molecules Incorporation into the Nano Polymeric Matrix (NPM) by Immersion of the Nano Polymeric Modified Electrode (NPME) as Molecular Enzymes and Drug Targets for Human Cancer Cells, Tissues and Tumors Treatment under Synchrotron and Synchrocyclotron Radiations", Int J Pharma Anal Acta 2(1): 007-014.

252. A Heidari (2018) "Fourier Transform Infrared (FTIR) Spectroscopy, Attenuated Total Reflectance Fourier Transform Infrared (ATR-FTIR) Spectroscopy, Micro-Attenuated Total Reflectance Fourier Transform Infrared (Micro-ATR-FTIR) Spectroscopy, Macro-Attenuated Total Reflectance Fourier Transform Infrared (Macro-ATR-FTIR) Spectroscopy, Two-Dimensional Infrared Correlation Spectroscopy, Linear Two-Dimensional Infrared Spectroscopy, Non-Linear TwoDimensional Infrared Spectroscopy, Atomic Force Microscopy Based Infrared (AFM-IR) Spectroscopy, Infrared Photodissociation Spectroscopy, Infrared Correlation Table Spectroscopy, Near-Infrared Spectroscopy (NIRS), Mid-Infrared Spectroscopy (MIRS), Nuclear Resonance Vibrational Spectroscopy, Thermal Infrared Spectroscopy and Photothermal Infrared Spectroscopy Comparative Study on Malignant and Benign Human Cancer Cells and Tissues under Synchrotron Radiation with the Passage of Time". Glob Imaging Insights 3(2): 1-14.

253. A Heidari (2018) "Heteronuclear Single-Quantum Correlation Spectroscopy (HSQC) and Heteronuclear Multiple-Bond Correlation Spectroscopy (HMBC) Comparative Study on Malignant and Benign Human Cancer Cells, Tissues and Tumors under Synchrotron and Synchrocyclotron Radiations". Chronicle of Medicine and Surgery 2(3): 144-156. 
254. A Heidari (2018) “Tetrakis [3, 5-bis (Trifluoromethyl) Phenyl] Borate (BARF)-Enhanced Precatalyst Preparation Stabilization and Initiation (EPPSI) Nano Molecules", Medical Research and Clinical Case Reports 2(1): 113-126.

255. A Heidari (2018) "Sydnone, Münchnone, Montréalone, Mogone, Montelukast, Quebecol and Palau'amine-Enhanced Precatalyst Preparation Stabilization and Initiation (EPPSI) Nano Molecules". Sur Cas Stud Op Acc J 1(3).

256. Heidari (2018) "Fornacite, Orotic Acid, Rhamnetin, Sodium Ethyl Xanthate (SEX) and Spermine (Spermidine or Polyamine) Nanomolecules Incorporation into the Nanopolymeric Matrix (NPM)". International Journal of Biochemistry and Biomolecules 4(1): 1-19.

257. A Heidari, R Gobato (2018) "Putrescine, Cadaverine, Spermine and Spermidine-Enhanced Precatalyst Preparation Stabilization and Initiation (EPPSI) Nano Molecules". Parana Journal of Science and Education (PJSE) 4(5): 1-14.

258. A Heidari (2018) “Cadaverine (1,5-Pentanediamine or Pentamethylenediamine), Diethyl Azodicarboxylate (DEAD or DEADCAT) and Putrescine (Tetramethylenediamine) Nano Molecules Incorporation into the Nano Polymeric Matrix (NPM) by Immersion of the Nano Polymeric Modified Electrode (NPME) as Molecular Enzymes and Drug Targets for Human Cancer Cells, Tissues and Tumors Treatment under Synchrotron and Synchrocyclotron Radiations". HIV and Sexual Health Open Access Open Journal 1(1): 4-11.

259. A Heidari (2018) "Improving the Performance of Nano-Endofullerenes in Polyaniline Nanostructure-Based Biosensors by Covering Californium Colloidal Nanoparticles with Multi- Walled Carbon Nanotubes". Journal of Advances in Nanomaterials 3(1): 1-28.

260. R Gobato, A Heidari (2018) "Molecular Mechanics and Quantum Chemical Study on Sites of Action of Sanguinarine Using Vibrational Spectroscopy Based on Molecular Mechanics and Quantum Chemical Calculations". Malaysian Journal of Chemistry 20(1): 1-23.

261. A Heidari (2018) "Vibrational Bio spectroscopic Studies on Anticancer Nano pharmaceuticals (Part I)". Malaysian Journal of Chemistry 20(1): 33-73.

262. A Heidari (2018) "Vibrational Bio spectroscopic Studies on Anti-cancer Nano pharmaceuticals (Part II)". Malaysian Journal of Chemistry 20(1): 74-117.

263. A Heidari (2018) "Uranocene (U(C8H8)2) and Bis (Cyclooctatetraene) Iron $(\mathrm{Fe}(\mathrm{C} 8 \mathrm{H} 8) 2$ or $\mathrm{Fe}(\mathrm{COT}) 2)$-Enhanced Precatalyst Preparation Stabilization and Initiation (EPPSI) Nano Molecules". Chemistry Reports 1(2): 1-16

264. A Heidari (2018) "Biomedical Systematic and Emerging Technological Study on Human Malignant and Benign Cancer Cells and Tissues Bio spectroscopic Analysis under Synchrotron Radiation". Glob Imaging Insights 3(3): 1-7.

265. A Heidari (2018) “Deep-Level Transient Spectroscopy and X-Ray Photoelectron Spectroscopy (XPS) Comparative Study on Malignant and Benign Human Cancer Cells and Tissues with the Passage of Time under Synchrotron Radiation". Res Dev Material Sci 7(2): RDMS.000659.

266. A Heidari (2018) "C70-Carboxyfullerenes Nano Molecules Incorporation into the Nano Polymeric Matrix (NPM) by Immersion of the Nano Polymeric Modified Electrode (NPME) as Molecular Enzymes and Drug Targets for Human Cancer Cells, Tissues and Tumors Treatment under Synchrotron and Synchrocyclotron Radiations". Glob Imaging Insights 3(3): 1-7.

267. A Heidari (2018) "The Effect of Temperature on Cadmium Oxide (CdO) Nanoparticles Produced by Synchrotron Radiation in the Human Cancer Cells, Tissues and Tumors". International Journal of Advanced Chemistry 6(2): 140-156.

268. A Heidari (2018)“A Clinical and Molecular Pathology Investigation of Correlation Spectroscopy (COSY), Exclusive Correlation Spectroscopy
(ECOSY), Total Correlation Spectroscopy (TOCSY), Heteronuclear Single-Quantum Correlation Spectroscopy (HSQC) and Heteronuclear Multiple-Bond Correlation Spectroscopy (HMBC) Comparative Study on Malignant and Benign Human Cancer Cells, Tissues and Tumors under Synchrotron and Synchrocyclotron Radiations Using Cyclotron versus Synchrotron, Synchrocyclotron and the Large Hadron Collider (LHC) for Delivery of Proton and Helium Ion (Charged Particle) Beams for Oncology Radiotherapy". European Journal of Advances in Engineering and Technology 5(7): 414-426.

269. A Heidari (2018) "Nano Molecules Incorporation into the Nano Polymeric Matrix (NPM) by Immersion of the Nano Polymeric Modified Electrode (NPME) as Molecular Enzymes and Drug Targets for Human Cancer Cells, Tissues and Tumors Treatment under Synchrotron and Synchrocyclotron Radiations". J Oncol Res 1(1): 1-20.

270. A Heidari (2018) "Use of Molecular Enzymes in the Treatment of Chronic Disorders". Canc Oncol Open Access J 1(1): 12-15.

271. A Heidari (2018) "Vibrational Bio spectroscopic Study and Chemical Structure Analysis of Unsaturated Polyamides Nanoparticles as AntiCancer Polymeric Nanomedicines Using Synchrotron Radiation". International Journal of Advanced Chemistry 6(2): 167-189.

272. A Heidari (2018) "Adamantane, Irene, Naftazone and PyridineEnhanced Precatalyst Preparation Stabilization and Initiation (PEPPSI) Nano Molecules". Madridge J Nov Drug Res 2(1): 61-67.

273. A Heidari (2018) "Heteronuclear Single-Quantum Correlation Spectroscopy (HSQC) and Heteronuclear Multiple-Bond Correlation Spectroscopy (HMBC) Comparative Study on Malignant and Benign Human Cancer Cells and Tissues with the Passage of Time under Synchrotron Radiation". Madridge J Nov Drug Res 2(1): 68-74.

274. A Heidari, R Gobato (2018) "A Novel Approach to Reduce Toxicities and to Improve Bioavailabilities of DNA/RNA of Human Cancer Cells-Containing Cocaine (Coke), Lysergide (Lysergic Acid Diethyl Amide or LSD), ${ }^{9}$-Tetrahydrocannabinol (THC) [(-)-trans- ${ }^{9}$ - Tetrahydrocannabinol], Theobromine (Xantheose), Caffeine, Aspartame (APM) (NutraSweet) and Zidovudine (ZDV) [Azidothymidine (AZT)] as Anti-Cancer Nano Drugs by Coassembly of Dual Anti-Cancer Nano Drugs to Inhibit DNA/RNA of Human Cancer Cells Drug Resistance". Parana Journal of Science and Education 4(6): 1-17.

275. A Heidari, R Gobato (2018) "Ultraviolet Photoelectron Spectroscopy (UPS) and Ultraviolet- Visible (UV-Vis) Spectroscopy Comparative Study on Malignant and Benign Human Cancer Cells and Tissues with the Passage of Time under Synchrotron Radiation". Parana Journal of Science and Education 4(6): 18-33.

276. R Gobato, A Heidari, A Mitra (2018) "The Creation of $\mathrm{C}_{1} 13 \mathrm{H}_{2} 0$ BeLi2 $\mathrm{SeSi}$. The Proposal of a Bio-Inorganic Molecule, Using Ab Initio Methods for the Genesis of a Nano Membrane" Arc Org In org Chem Sci 3(4): AOICS.MS.ID.000167.

277. R Gobato, A Heidari, A Mitra (2018) “Using the Quantum Chemistry for Genesis of a Nano Bio membrane with a Combination of the Elements Be, Li, Se, Si, C and H". p.15.

278. R Gobato, A Heidari (2018) "Using the Quantum Chemistry for Genesis of a Nano Bio membrane with a Combination of the Elements Be, $\mathrm{Li}, \mathrm{Se}$, Si, C and H", J Nanomed Res 7(4): 241-252.

279. A Heidari (2018) "Bastadins and Bastaranes-Enhanced Precatalyst Preparation Stabilization and Initiation (EPPSI) Nano Molecules". Glob Imaging Insights 3(4): 1-7.

280. A Heidari (2018) "Fucitol, Pterodactyl diene, DEAD or DEADCAT (DiEthyl AzoDiCArboxylaTe), Skatole, the NanoPutians, Thebacon, Pikachurin, Tie Fighter, Spermidine and Mirasorvone Nano Molecules Incorporation into the Nano Polymeric Matrix (NPM) by Immersion of the Nano Polymeric Modified Electrode (NPME) as Molecular Enzymes and Drug Targets for Human Cancer Cells, Tissues and Tumors Treatment under Synchrotron and Synchrocyclotron Radiations". Glob Imaging Insights 3(4): 1-8. 
281. E Dadvar, A Heidari (2018) "A Review on Separation Techniques of Graphene Oxide (GO)/Base on Hybrid Polymer Membranes for Eradication of Dyes and Oil Compounds: Recent Progress in Graphene Oxide (GO)/Base on Polymer Membranes-Related Nanotechnologies". Clin Med Rev Case Rep 5: 228.

282. A Heidari, R Gobato (2018) "First-Time Simulation of Deoxyuridine Monophosphate (dUMP) (Deoxyuridylic Acid or Deoxyuridylate) and Vomitoxin (Deoxynivalenol (DON)) $((3 \alpha, 7 \alpha)$ - 3,7,15-Trihydroxy-12,13 Epoxytrichothec-9-En-8-One)-Enhanced Precatalyst Preparation Stabilization and Initiation (EPPSI) Nano Molecules Incorporation into the Nano Polymeric Matrix (NPM) by Immersion of the Nano Polymeric Modified Electrode (NPME) as Molecular Enzymes and Drug Targets for Human Cancer Cells, Tissues and Tumors Treatment under Synchrotron and Synchrocyclotron Radiations". Parana Journal of Science and Education 4(6): 46-67.

283. A Heidari (2018) "Buckminsterfullerene (Fullerene), Bullvalene, Dickite and Josiphos Ligands Nano Molecules Incorporation into the Nano Polymeric Matrix (NPM) by Immersion of the Nano Polymeric Modified Electrode (NPME) as Molecular Enzymes and Drug Targets for Human Hematology and Thromboembolic Diseases Prevention, Diagnosis and Treatment under Synchrotron and Synchrocyclotron Radiations". Glob Imaging Insights 3(4): 1-7.

284. A Heidari (2018) "Fluctuation X-Ray Scattering (FXS) and Wide-Angle X-Ray Scattering (WAXS) Comparative Study on Malignant and Benign Human Cancer Cells and Tissues under Synchrotron Radiation". Glob Imaging Insights 3(4): 1-7.

285. A Heidari (2018) "A Novel Approach to Correlation Spectroscopy (COSY), Exclusive Correlation Spectroscopy (ECOSY), Total Correlation Spectroscopy (TOCSY), Incredible Natural-Abundance DoubleQuantum Transfer Experiment (INADEQUATE), Heteronuclear SingleQuantum Correlation Spectroscopy (HSQC), Heteronuclear MultipleBond Correlation Spectroscopy (HMBC), Nuclear Overhauser Effect Spectroscopy (NOESY) and Rotating Frame Nuclear Overhauser Effect Spectroscopy (ROESY) Comparative Study on Malignant and Benign Human Cancer Cells and Tissues under Synchrotron Radiation". Glob Imaging Insights 3(5): 1-9.

286. A Heidari (2018) "Terphenyl-Based Reversible Receptor with Rhodamine, Rhodamine-Based Molecular Probe, Rhodamine-Based Using the Spirolactam Ring Opening, Rhodamine B with Ferrocene Substituent, Calix[4]Arene-Based Receptor, Thioether + AnilineDerived Ligand Framework Linked to a Fluorescein Platform, Mercuryfluor-1 (Flourescent Probe), N,N'- Dibenzyl-1,4,10,13Tetraraoxa-7,16-Diazacyclooctadecane and Terphenyl-Based Reversible Receptor with Pyrene and Quinoline as the FluorophoresEnhanced Precatalyst Preparation Stabilization and Initiation (EPPSI) Nano Molecules". Glob Imaging Insights 3(5): 1-9.

287. A Heidari (2018) "Small-Angle X-Ray Scattering (SAXS), Ultra-Small Angle X-Ray Scattering (USAXS), Fluctuation X-Ray Scattering (FXS) Wide-Angle X-Ray Scattering (WAXS), Grazing-Incidence SmallAngle X-Ray Scattering (GISAXS), Grazing-Incidence Wide-Angle X-Ray Scattering (GIWAXS), Small-Angle Neutron Scattering (SANS), Grazing-Incidence Small-Angle Neutron Scattering (GISANS), X-Ray Diffraction (XRD), Powder X-Ray Diffraction (PXRD), Wide-Angle X-Ray Diffraction (WAXD), Grazing-Incidence X-Ray Diffraction (GIXD) and Energy-Dispersive X-Ray Diffraction (EDXRD) Comparative Study on Malignant and Benign Human Cancer Cells and Tissues under Synchrotron Radiation". Glob Imaging Insights 3(5): 1-10.

288. A Heidari (2018) "Nuclear Resonant Inelastic X-Ray Scattering Spectroscopy (NRIXSS) and Nuclear Resonance Vibrational Spectroscopy (NRVS) Comparative Study on Malignant and Benign Human Cancer Cells and Tissues under Synchrotron Radiation", Glob Imaging Insights 3(5): 1-7.

289. A Heidari (2018) "Small-Angle X-Ray Scattering (SAXS) and Ultra-Small Angle X-Ray Scattering (USAXS) Comparative Study on Malignant and Benign Human Cancer Cells and Tissues under Synchrotron Radiation". Glob Imaging Insights 3(5): 1-7.
290. A Heidari (2018) "Curious Chloride $\left(\mathrm{CmCl}_{3}\right)$ and Titanic Chloride (TiCl4)-Enhanced Precatalyst Preparation Stabilization and Initiation (EPPSI) Nano Molecules for Cancer Treatment and Cellular Therapeutics". J Cancer Research and Therapeutic Interventions 1(1): 1-10.

291. R Gobato, MRR Gobato, A Heidari, A Mitra (2018) "Spectroscopy and Dipole Moment of the Molecule $\mathrm{C}_{13} \mathrm{H}_{20 \mathrm{BeLi}} \mathrm{SeSi}$ via Quantum Chemistry Using Ab Initio, Hartree-Fock Method in the Base Set CCpVTZ and 6-311G**(3df, 3pd)". Arc Org Inorg Chem Sci 3(5): 402-409.

292. A Heidari (2018) "C60 and C70-Encapsulating Carbon Nanotubes Incorporation into the Nano Polymeric Matrix (NPM) by Immersion of the Nano Polymeric Modified Electrode (NPME) as Molecular Enzymes and Drug Targets for Human Cancer Cells, Tissues and Tumors Treatment under Synchrotron and Synchrocyclotron Radiations". Integr Mol Med 5(3): 1-8.

293. A Heidari (2018) “Two-Dimensional (2D) H or Proton NMR, C NMR, N NMR and P NMR Spectroscopy Comparative Study on Malignant and Benign Human Cancer Cells and Tissues under Synchrotron Radiation with the Passage of Time". Glob Imaging Insights 3 (6): 1-8.

294. A Heidari (2018) "FT-Raman Spectroscopy, Coherent Anti-Stokes Raman Spectroscopy (CARS) and Raman Optical Activity Spectroscopy (ROAS) Comparative Study on Malignant and Benign Human Cancer Cells and Tissues with the Passage of Time under Synchrotron Radiation". Glob Imaging Insights 3(6): 1-8.

295. A Heidari (2018) "A Modern and Comprehensive Investigation of Inelastic Electron Tunneling Spectroscopy (IETS) and Scanning Tunneling Spectroscopy on Malignant and Benign Human Cancer Cells, Tissues and Tumors through Optimizing Synchrotron Microbeam Radiotherapy for Human Cancer Treatments and Diagnostics: An Experimental Bio Spectroscopic Comparative Study". Glob Imaging Insights 3(6): 1-8.

296. A Heidari (2018) "A Hypertension Approach to Thermal Infrared Spectroscopy and Photothermal Infrared Spectroscopy Comparative Study on Malignant and Benign Human Cancer Cells and Tissues under Synchrotron Radiation with the Passage of Time". Glob Imaging Insights 3(6): 1-8.

297. A Heidari (2018) "Incredible Natural-Abundance Double-Quantum Transfer Experiment (INADEQUATE), Nuclear Overhauser Effect Spectroscopy (NOESY) and Rotating Frame Nuclear Overhauser Effect Spectroscopy (ROESY) Comparative Study on Malignant and Benign Human Cancer Cells and Tissues under Synchrotron Radiation". Glob Imaging Insight 3(6): 1-8.

298. A Heidari (2018) "2-Amino-9-((1S, 3R, 4R)-4-Hydroxy-3(Hydroxymethyl)-2- Methylenecyclopentyl)-1H-Purin-6(9H)One, 2-Amino-9-((1R, 3R, 4R)-4-Hydroxy-3- (Hydroxymethyl)2-Methylenecyclopentyl)-1H-Purin-6(9H)-One, 2-Amino-9-((1R, 3R, 4S)- 4-Hydroxy-3-(Hydroxymethyl)-2-Methylenecyclopentyl)1H-Purin-6(9H)-One and 2-Amino- 9-((1S, 3R, 4S)-4-Hydroxy-3(Hydroxymethyl)-2-Methylenecyclopentyl)-1H-Purin-6(9H)- OneEnhanced Precatalyst Preparation Stabilization and Initiation Nano Molecules". Glob Imaging Insights 3(6): 1-9.

299. R Gobato, MRR Gobato, A Heidari, A Mitra (2018) "Spectroscopy and Dipole Moment of the Molecule $\mathrm{C}_{13} \mathrm{H}_{20 \mathrm{BeLi}} \mathrm{SeSi}$ via Quantum Chemistry Using $\mathrm{Ab}$ Initio, Hartree-Fock Method in the Base Set CC-pVTZ and 6-311G**(3df, 3pd)". American Journal of Quantum Chemistry and Molecular Spectroscopy 2(1): 9-17.

300. A Heidari (2018) "Production of Electrochemiluminescence (ECL) Biosensor Using Os-Pd/HfC Nanocomposites for Detecting and Tracking of Human Gastroenterological Cancer Cells, Tissues and Tumors". Int J Med Nano Res 5(1): 022-034.

301. A Heidari (2018) "Enhancing the Raman Scattering for Diagnosis and Treatment of Human Cancer Cells, Tissues and Tumors Using Cadmium Oxide (CdO) Nanoparticles". J Toxicol Risk Assess 4(1): 012-025. 
302. A Heidari (2018) "Human Malignant and Benign Human Cancer Cells and Tissues Biospectroscopic Analysis under Synchrotron Radiation Using Anti-Cancer Nano Drugs Delivery". Integr Mol Med 5(5): 1-13.

303. A Heidari (2018) "Analogous Nano Compounds of the Form M(C8H8)2 Exist for $\mathrm{M}=(\mathrm{Nd}, \mathrm{Tb}, \mathrm{Pu}, \mathrm{Pa}, \mathrm{Np}$, Th, and $\mathrm{Yb})$-Enhanced Precatalyst Preparation Stabilization and Initiation (EPPSI) Nano Molecules". Integr Mol Med 5(5): 1-8.

304. A Heidari (2018) "Hadron Spectroscopy, Baryon Spectroscopy and Meson Spectroscopy Comparative Study on Malignant and Benign Human Cancer Cells and Tissues under Synchrotron Radiation". Integr Mol Med 5(5): 1-8.

305. MRR Gobato, A Heidari (2019) "Raman Spectroscopy Study of the Nano Molecule $\mathrm{C}_{13} \mathrm{H}_{20 \mathrm{BeLi}} \mathrm{SeSi}$ Using ab initio and Hartree-Fock Methods in the Basis Set CC-pVTZ and 6-311G** (3df, 3pd)". International Journal of Advanced Engineering and Science 7(1) 14-35.

306. R Gobato, A Heidari (2019) "Evaluating the Effect of Anti-Cancer Nano Drugs Dosage and Reduced Leukemia and Polycythemia Vera Levels on Trend of the Human Blood and Bone Marrow Cancers under Synchrotron Radiation". Trends in Res 2(1): 1-8.

307. A Heidari, R Gobato (2019) "Assessing the Variety of Synchrotron, Synchrocyclotron and LASER Radiations and Their Roles and Applications in Human Cancer Cells, Tissues and Tumors Diagnosis and Treatment". Trends in Res 2(1): 1-8.

308. R Gobato, A Heidari (2019) "Pros and Cons Controversy on Malignant Human Cancer Cells, Tissues and Tumors Transformation Process to Benign Human Cancer Cells, Tissues and Tumors". Trends in Res 2(1): $1-8$.

309. A Heidari, R Gobato (2019) "Three-Dimensional (3D) Simulations of Human Cancer Cells, Tissues and Tumors for Using in Human Cancer Cells, Tissues and Tumors Diagnosis and Treatment as a Powerful Tool in Human Cancer Cells, Tissues and Tumors Research and Anti- Cancer Nano Drugs Sensitivity and Delivery Area Discovery and Evaluation". Trends in Res 2(1): 1-8.

310. A Heidari, R Gobato (2019) "Investigation of Energy Production by Synchrotron, Synchrocyclotron and LASER Radiations in Human Cancer Cells, Tissues and Tumors and Evaluation of Their Effective on Human Cancer Cells, Tissues and Tumors Treatment Trend", Trends in Res 2(1): 1-8.

311. A Heidari, R Gobato (2019) "High-Resolution Mapping of DNA/RNA Hypermethylation and Hypomethylation Process in Human Cancer Cells, Tissues and Tumors under Synchrotron Radiation". Trends in
Res 2(2): 1-9.

312. A Heidari (2019) "A Novel and Comprehensive Study on Manufacturing and Fabrication Nanoparticles Methods and Techniques for Processing Cadmium Oxide (CdO) Nanoparticles Colloidal Solution". Glob Imaging Insights 4(1): 1-8.

313. A Heidari (2019) "A Combined Experimental and Computational Study on the Catalytic Effect of Aluminum Nitride Nanocrystal (AlN) on the Polymerization of Benzene, Naphthalene, Anthracene, Phenanthrene, Chrysene and Tetracene". Glob Imaging Insights 4(1): 1- 8.

314. A Heidari (2019) “Novel Experimental and Three-Dimensional (3D) Multiphysics Computational Framework of Michaelis-Menten Kinetics for Catalyst Processes Innovation, Characterization and Carrier Applications". Glob Imaging Insights 4(1): 1-8.

315. A Heidari (2019) “The Hydrolysis Constants of Copper (I) $\left(\mathrm{Cu}^{+}\right.$) and Copper (II) $\left(\mathrm{Cu}^{2+}\right)$ in Aqueous Solution as a Function of $\mathrm{pH}$ Using a Combination of $\mathrm{pH}$ Measurement and Bio spectroscopic Methods and Techniques", Glob Imaging Insights 4(1): 1-8.

316. A Heidari (2019) "Vibrational Bio spectroscopic Study of Ginormous Virus-Sized Macromolecule and Polypeptide Macromolecule as Mega Macromolecules Using Attenuated Total Reflectance-Fourier Transform Infrared (ATR-FTIR) Spectroscopy and Mathematica 11.3". Glob Imaging Insights 4(1): 1-8.

317. A Heidari (2019) "Three-Dimensional (3D) Imaging Spectroscopy of Carcinoma, Sarcoma, Leukemia, Lymphoma, Multiple Myeloma, Melanoma, Brain and Spinal Cord Tumors, Germ Cell Tumors, Neuroendocrine Tumors and Carcinoid Tumors under Synchrotron Radiation", Glob Imaging Insights 4(1): 1-9.

318. R Gobato, MRR Gobato, A Heidari, A Mitra (2019) "New NanoMolecule Kurumi-C13H 20BeLi2SeSi/C13H19BeLi2SeSi, and Raman Spectroscopy Using ab initio, Hartree-Fock Method in the Base Set CCpVTZ and 6-311G** (3df, 3pd)". J Anal Pharm Res 8(1): 1-6.

319. A Heidari, J Esposito, A Caissutti (2019) “The Importance of Attenuated Total Reflectance Fourier Transform Infrared (ATR-FTIR) and Raman Biospectroscopy of Single-Walled Carbon Nanotubes (SWCNT) and Multi-Walled Carbon Nanotubes (MWCNT) in Interpreting Infrared and Raman Spectra of Human Cancer Cells, Tissues and Tumors" Oncogen 2(2): 1-21.

320. A Heidari, J Esposito, A Caissutti (2019) "Study of Anti-Cancer Properties of Thin Layers of Cadmium Oxide (CdO) Nanostructure". Int J Analyt Bioanalyt Methods 1(1): 1-20. 